\title{
Comparison of adsorption equilibrium models and error functions for the study of sulfate removal by calcium hydroxyapatite microfibrillated cellulose composite
}

\author{
Sanna Hokkanen, Amit Bhatnagar, Ari Koistinen, Teija Kangas, Ulla Lassi \& \\ Mika Sillanpää
}

To cite this article: Sanna Hokkanen, Amit Bhatnagar, Ari Koistinen, Teija Kangas, Ulla Lassi \& Mika Sillanpää (2017): Comparison of adsorption equilibrium models and error functions for the study of sulfate removal by calcium hydroxyapatite microfibrillated cellulose composite, Environmental Technology, DOI: 10.1080/09593330.2017.1317839

To link to this article: http://dx.doi.org/10.1080/09593330.2017.1317839

Accepted author version posted online: 13

Apr 2017.

Submit your article to this journal $₫$

Џ Article views: 4

View related articles $\sqsubset \pi$

View Crossmark data ־ 
Publisher: Taylor \& Francis \& Informa UK Limited, trading as Taylor \& Francis Group

Journal: Environmental Technology

DOI: $10.1080 / 09593330.2017 .1317839$

Comparison of adsorption equilibrium models and error functions for the study of sulfate removal by calcium hydroxyapatite microfibrillated cellulose composite

Sanna Hokkanen ${ }^{1}$, Amit Bhatnagar ${ }^{2}$, Ari Koistinen ${ }^{3}$, Teija Kangas ${ }^{4}$, Ulla Lassi ${ }^{4,5}$ Mika Sillanpää ${ }^{1}$

${ }^{1}$ Laboratory of Green Chemistry, School of Engineering Science, Lappeenranta University of Technology, Sammonkatu 12, FI-50130 Mikkeli, Finland, Phone: (+358) 40747 7843, Fax (+358) 15-336-013 E-mail: Sanna.Hokkanen@lut.fi

${ }^{2}$ Department of Environmental and Biological Sciences, University of Eastern Finland, P.O. Box 1627, FI-70211, Kuopio, Finland

${ }^{3}$ Department of Mechanical Engineering, Helsinki Metropolia University of Applied Sciences, P. O. Box 4021, Fl-00079, Helsinki, Finland

${ }^{4}$ Research Unit of Sustainable Chemistry, University of Oulu, P.O. Box 3000, FI-90014, University of Oulu.

University of Jyvaskyla, Kokkola University Consortium Chydenius, Unit of Applied Chemistry, Talonpojankatu 2B, FI-67100 Kokkola, Finland

\section{Abstract}


In the present study, the adsorption of sulfates of sodium sulfate $\left(\mathrm{Na}_{2} \mathrm{SO}_{4}\right)$ and sodium lauryl sulfate (SLS) by calcium hydroxyapatite (CHA) modified microfibrillated cellulose (MFC) was studied in the aqueous solution. The adsorbent was characterized using elemental analysis, Fourier transform infrared (FTIR), scanning electron microscope (SEM) and elemental analysis in order to gain the information on its structure and physico-chemical properties. The adsorption studies were conducted in batch mode. The effects of solution ph, contact time, the initial concentration of sulfate and the effect of competing anions were studied on the performance of synthesized adsorbent for sulfate removal Adsorption kinetics indicated very fast adsorption rate for sulfate of both sources $\left(\mathrm{Na}_{2} \mathrm{SO}_{4}\right.$ and $\left.\mathrm{SLS}\right)$ and the adsorption process was well described by the pseudo-second-order kinetic model. Experimental maximum adsorption capacities were found to be $34.53 \mathrm{mg} / \mathrm{g}$ for sulfates of $\mathrm{SLS}$ and $7.35 \mathrm{mg} / \mathrm{g}$ for sulfates of $\mathrm{Na}_{2} \mathrm{SO}_{4}$. The equilibrium data were described by the Langmuir, Sips, Freundlich, Toth and Redlich-Peterson isotherm models using five different error functions.

Keywords: Adsorption; Calcium hydroxyapatite (CHA); nanocellulose; water treatment; sulfate removal.

\section{Introduction}

Sulfate is a common contaminant of wastewater effluent. The wastewater originating from animal husbandry, mining and food processing is usually highly polluted with sulfate [1]. High concentration of sulfate-based compounds in drinking water raise serious health risks 
and cause environmental deterioration [2]. High sulfate concentrations in drinking water can cause diarrhea and dehydration [3]. Sulfates are also related to the occurrence of piping and equipment corrosion. When these effluents are discharged into the environment, they may increase the acidity of both soils and water bodies [2]. Due to these adverse effects on human health and the environment, mining industries usually set limits for sulfate concentrations in waters and wastewaters ranging from $250 \mathrm{mg} \mathrm{L}^{-1}$ to $500 \mathrm{mg} \mathrm{L}^{-1}[4,5]$.

On the other hand, surfactants are the active ingredients of hygiene products and detergents for industrial and household cleaning. They are one of the most common organic pollutants characterized with very high potential to enter the environment due to their wide use in daily life mainly in household applications and as industrial cleaning agents. Surfactants are primarily present in aqueous solutions, which lead to introduction into the environment via wastewater discharges [6]. Sodium lauryl sulfate (SLS) is widely used as anionic surfactant in several products such as shampoos, detergents and toothpaste due to its relatively low cost [7]. It has been shown that SLS causes eye or skin irritation in experiments of done on animals and humans [7]. The research suggests that SLS can also cause irritation after extended exposure in some people [7]. Therefore, robust water treatment is necessary in order to remove elevated concentrations of sulfates and surfactant from industrial and domestic wastes to reduce their concentrations.

Recently, a number of methods such as chemical precipitation, ion exchange, reverse osmosis, nano-filtration, electro-dialysis, crystallization, distillation and evaporation have been used for the removal of sulfates and surfactant from wastewaters [5, 6, 8-12]. Chemical precipitation is a widely used, proven technology for the removal of sulfates but 
this method has some limitation such as, the production of high sludge volume and $\mathrm{pH}$ adjustment of treated water. On the other hand, ion exchange and membrane separation are considered to be expensive technologies due to the high operational costs $[5,13]$. Adsorption has been proved as one of the most efficient methods for the removal of different pollutants from aqueous media. At present, research interests into the production of alternative adsorbents to replace costly synthetic resins have intensified in recent years. Sulfate removal by shrimp peelings [14], modified cellulose contained in sugarcane bagasse [15] and rice straw [16], coconut pith [17], limestone [18] and modified zeolites [6] has been studied. In this context, the advantages of using cellulose based materials as the basis for new adsorbent design lie primarily in its high abundance and low cost. The chemically modification is usually necessary in order to achieve a better adsorption capacity. However, the use of the catalyst and the organic solvent will inevitably impair the product's cost advantage promised by its abundant and renewable raw material. Most of these chemicals are also harmful for the environment.

We have presented, in our previous study, that the calcium hydroxyapatite $(\mathrm{CHA})$ modified microfibrillated cellulose (MFC) is an easily handled, natural and environmentally friendly adsorbent with excellent removal efficiency for metals and phosphorus, moderate removal efficiency for nitrates [19]. The aim of this work is to study the removal of an anionic surfactant (SLS) and sulfate from aqueous solution by adsorption on CHA/MFC and to assess the parameters that influence the sulfate and surfactant adsorption. The most common isotherm equations namely Langmuir, Sips, Freundlich, Toth and Redlich-Peterson were used for analyze the experimental data. Another purpose of this work was to stimulate discussion about usefulness of commonly used error functions for comparing the fit of isotherms. The 
comparison of five different error functions in minimizing the error distribution between the experimental and predicted isotherms was discussed using the experimental data of adsorption.

\section{Materials and methods}

Unmodified MFC, commercial microfibrillated cellulose KY 100G, was obtained from Daicel Industries Ltd. The crystallinity index of the pulp was $66 \%$ and an average particle size measured by a laser diffractometer (Beckman Coulter LS 13 320) was $75 \mu \mathrm{m}$. All solutions were prepared in Millipore milliQ high purity water. All chemicals used in this study were of analytical grade and supplied by Sigma-Aldrich (Germany). Sulfate and SLS stock solutions of $1000 \mathrm{mg} / \mathrm{L}$ were prepared by dissolving appropriate amounts of $\mathrm{Na}_{2} \mathrm{SO}_{4}$ salt and $\mathrm{C}_{12} \mathrm{H}_{25} \mathrm{NaO}_{4} \mathrm{~S}$ salt in deionized water.

\subsection{Synthesis of CHA modified MFC}

The solution containing MFC ( $3.0 \mathrm{~g}), \mathrm{NaOH}(15.0 \mathrm{~g})$ and distilled water $(100 \mathrm{~mL})$, were mixed under magnetic stirring for $5 \mathrm{~min}$ at room temperature. After that, the solution was cooled to $5^{\circ} \mathrm{C}$ for $12 \mathrm{~h}[19-21]$.

$50 \mathrm{~mL}$ of cooled MFC- $\mathrm{NaOH}$ solution was mixed with the solution containing $25 \mathrm{~mL}$ of $\mathrm{CaCl}_{2} \cdot 2 \mathrm{H}_{2} \mathrm{O}(0.402 \mathrm{~mol} / \mathrm{L})$ and $25 \mathrm{~mL}$ of $\mathrm{NaH}_{2} \mathrm{PO}_{4} \cdot \mathrm{H}_{2} \mathrm{O}(0.802 \mathrm{~mol} / \mathrm{L})$ under vigorous stirring at room temperature for $2 \mathrm{~h}$. After stirring the mixture was transferred into an oven at $160^{\circ} \mathrm{C}$ for $6 \mathrm{~h}$. The mixture was centrifuged at $4000 \mathrm{rpm}$ for $5 \mathrm{~min}$. CHA/MFC mixture was washed four times by water - ethanol mixture and centrifuged [19-21]. 


\subsection{Characterization of modified MFC}

Fourier transform infrared spectroscopy (FTIR) spectra of CHA/MFC were obtained using Vertex 70 by Bruker Optics (Germany). An attenuated total reflection (ATR-FTIR) spectra were accomplished at $4 \mathrm{~cm}^{-1}$ resolution from 400 to $4000 \mathrm{~cm}^{-1}$ and 100 scans per sample. The surface morphology and chemical composition of $\mathrm{CHA} / \mathrm{MFC}$ was examined using a Hitachi S-4100 scanning electron microscope (SEM) and energy dispersive analysis of X-rays (EDAX), respectively. The surface charge and point of zero charge of the modified and unmodified cellulose were determined by isoelectric point titration as a function of $\mathrm{pH}$ by using ZetasizerNano ZS (ZEN3500, Malvern).

\subsection{Batch adsorption experiments}

Potential of $\mathrm{CHA} / \mathrm{MFC}$ for sulfate removal from aqueous solution was studied using batch experiments in a reaction mixture of $0.030 \mathrm{~g}$ of adsorbent and $0.005 \mathrm{~L}$ of $\mathrm{Na}_{2} \mathrm{SO}_{4}$ and SLS solution at sulfate concentration ranging from 25 to $500 \mathrm{mg} \mathrm{L}^{-1}$. The effect of contact time was studied in two reaction mixtures of $3.75 \mathrm{~g} \mathrm{~L}^{-1}$ of adsorbent and $0.200 \mathrm{~L}$ of solution containing 120 and $250 \mathrm{mg} \mathrm{L}^{-1}$ sulfate of $\mathrm{Na}_{2} \mathrm{SO}_{4}$ and SLS, respectively. Blending of the reaction mixture was accomplished under mechanic stirring. $2 \mathrm{~mL}$ samples were pipetted with plastic syringe from the reaction mixtures according to schedule. The experiments were conducted at room temperature. The contact time was varied from 5 to $600 \mathrm{~min}$.

Sulfate concentrations were analyzed by an inductively coupled plasma optical atomic emission spectrometry (ICP-OES) model iCAP 6300 (Thermo Electron Corporation, USA). The 
adsorption capacity $\left(\mathrm{q}_{\mathrm{e}}, \mathrm{mg} / \mathrm{g}\right.$ ) and removal efficiency (\%) were calculated by Eqs. (1) and (2), respectively.

$$
\begin{gathered}
q_{e}=\frac{\left(C_{i}-C_{e}\right)}{m} V \\
n(\%)=\frac{\left(C_{i}-C_{e}\right)}{C_{i}} \times 100
\end{gathered}
$$

where, $C_{0}$ and $C_{e}$ are the initial and equilibrium concentrations of sulfate and surfactant $\left(\mathrm{mmol} \mathrm{L}{ }^{-1}\right)$ respectively, $m$ is the weight of the adsorbent $(\mathrm{g})$ and $V$ is the volume of the solution (L).

Effect of initial solution $\mathrm{pH}$ on adsorption was studied using $\mathrm{Na}_{2} \mathrm{SO}_{4}$ and $\mathrm{SLS}$ with initial $\mathrm{SO}_{4}$ concentration of 125 and $250 \mathrm{mg} \mathrm{L}^{-1}$, respectively, in the $\mathrm{pH}$ range of 3.0-8.0 at $305 \mathrm{~K}$. The $\mathrm{pH}$ of the solution during batch adsorption was not adjusted (except $\mathrm{pH}$ dependent isotherm study) by adding either acid or base. But, final $\mathrm{pH}$ of solution at equilibrium point for each batch experiment was noted.

Effects of individual competitive ions like, phosphate $\left(\mathrm{NaHPO}_{4}\right)$, nitrate $\left(\mathrm{NaNO}_{3}\right)$ and chloride $\left(\mathrm{NH}_{4} \mathrm{Cl}\right)$ on $\mathrm{Na}_{2} \mathrm{SO}_{4}$ and SLS adsorption were studied in batch mode at $\mathrm{pH}$ 2-9 and $305 \mathrm{~K}$ with $6 \mathrm{~g} \mathrm{~L}^{-1}$ adsorbent dose using $5 \mathrm{~mL}$ solution containing following combination of ions: $200.0 \mathrm{mg} \mathrm{L}^{1}$ sulfate, chloride, nitrate, and phosphate respectively. 


\subsection{Theoretical method}

\subsubsection{Kinetics}

Kinetic characteristic of an adsorbent depends on the presence of active sites and the ease of access of the adsorbed ions onto the active site without sterical hindrance which is greatly determined by the matrices of the adsorbent $[21,22]$. The sorption mechanism depends on the physical and chemical characteristics of the adsorbent as well as on the mass transfer process. In order to investigate the mechanisms of the sulfate adsorption process, various kinetic models were applied to describe the adsorption kinetics onto CHA/MFC.

\section{Pseudo first-order kinetic model}

The pseudo-first order kinetic model can be given as:

$\frac{d q}{d t}=k_{1}\left(q_{e}-q_{t}\right)$

where $k_{1}\left(\min ^{-1}\right)$ is the rate constant of adsorption, $q_{t}$ and $q_{e}$ are the adsorbed amounts at a given time $t$ and at equilibrium ( $\mathrm{mg} \mathrm{g}^{-1}$ ) respectively [19-23]. After integration between 0 and a given time $t$, it comes:

$$
\ln \left(\frac{q_{e}-q_{t}}{q_{e}}\right)=-K_{1} t
$$


which can be rearranged to give:

$\ln \left(q_{e}-q_{t}\right)=\ln q_{e}-K_{1} t$

\section{Pseudo second-order kinetic model}

The pseudo-second-order model is based on the assumption that sorption follows a secondorder mechanism, whereby the rate of sorption is proportional to the square of the number of unoccupied sites [21, 23-27].

$\frac{d q}{d t}=k_{2}\left(q_{e}-q_{t}\right)^{2}$

where $k_{2}$ is the rate constant of the pseudo-second order model $\left(\mathrm{g} \mathrm{mg}^{-1} \mathrm{~min}^{-1}\right)$.

The linearized form of Eq. 6 is expressed as

$$
\frac{t}{q_{t}}=\frac{1}{K_{2} q_{e}^{2}}+\frac{t}{q_{e}}(7)
$$

\subsubsection{Adsorption isotherms}

Single-component sorption models 
The equilibrium between a solute and an adsorbent surface is commonly represented by single-component adsorption isotherms, basically considering the following surface complexation reaction

$R+X \leftrightarrows R X R+X \leftrightarrows R X$

(8)

where $R$ represents the sorbent in its initial form, $X$ is the aqueous phase species, and $R X$ is the species $X$ in the resin phase $[21,27]$.

\section{Langmuir isotherm}

The Langmuir relates the amount of solid adsorbate adsorbed, $q_{e}$, to the equilibrium liquid concentration at a fixed temperature $[19-21,29,30]$. It is semi-empirical model and derives from Eq. (8) assuming a monolayer adsorption phenomenon on a homogeneous surface. Considering Eq. (8) at equilibrium, the Langmuir parameter $k_{\mathrm{L}}\left(\mathrm{L} \mathrm{mg}^{-1}\right)$ representing the equilibrium constant can be expressed as

$$
\mathrm{k}_{\mathrm{L}}=[\mathrm{RX}] /[\mathrm{R}][\mathrm{X}]
$$

At equilibrium, the Langmuir equation arises from Eq. (8) considering $X_{\mathrm{aq}}=C_{\mathrm{e}} ; R X=q_{\mathrm{e}}$; and

$\mathrm{R}=q_{0}-q_{\mathrm{e}}$, where $q_{0}\left(\mathrm{mg} \mathrm{g}^{-1}\right)$ represents the maximum capacity of the resin. Eq. (9) then becomes,

$$
k_{L}=\frac{q_{e}}{\left(q_{0}-q_{e}\right) C_{e}}(10)
$$


And a simple modification leads to following

$q_{e}=\frac{k_{L} q_{e} C_{e}}{1+k_{L} C_{e}}(11)$

and denoting $a=\frac{1}{K_{L}}$ it can be also expressed as

$q_{e}=\frac{q_{m} C_{e}}{a+C_{e}}$

\section{Freundlich isotherm}

The Freundlich isotherm [32] is an empirical model which doesn't imply a maximum adsorption capacity of the sorbent. The model based on the following equation:

$$
q_{e}=k_{F} C_{e}^{1 / n_{F}}(13)
$$

where $k_{\mathrm{F}}\left(\mathrm{mg}^{1-1 / n_{\mathrm{F}}} \mathrm{L}^{1 / n_{\mathrm{F}}} \mathrm{g}^{-1}\right)$ and $n_{\mathrm{F}}$ (dimensionless) are the Freundlich constants determined from the nonlinear regression. The value of the parameter $n_{\mathrm{F}}$ is representative of both the adsorption intensity and the surface heterogeneity.

Despite the parameter $n_{F}$ devoid of physical meaning, it is generally accepted that $0<1 / n_{\mathrm{F}}<1$ indicates favourable adsorption, while $1 / n_{\mathrm{F}}=1$ indicates a linear adsorption 
phenomenon, $1 / n_{F}>1$, it is difficulty to adsorb. The Freundlich constants $n_{F}$ and $k_{F}$ appear to incorporate all the physico-chemical factors influencing the adsorption process [23, 32].

\section{Sips isotherm}

Langmuir also considered the case of a molecule occupying two sites. In such cases, a derivative of the original Langmuir isotherm can be determined assuming that the rates of adsorption and desorption are proportional to $(1-\theta)^{2}$ and $\theta^{2}$, respectively, where $\theta$ is the fractional surface coverage [33]. Therefore, the rate equation becomes:

$$
\frac{d \theta}{d t}=k_{a} C(1-\theta)^{2}-k_{d} \theta^{2}
$$

Generalising to $m=(1 / n)$ sites and assuming equilibrium produces the Sips sorption isotherm [34]. In brief, Sips isotherm model is obtained by introducing a power law expression of the Freundlich equation into the Langmuir equation. The non-linearized form of Sips isotherm model can be given as follows:

$$
q_{e}=\frac{q_{m}\left(K_{s} C_{e}\right)^{n_{s}}}{1+\left(K_{s} C_{e}\right)^{n_{s}}}
$$

which, if denoting $a=\left(\frac{1}{K_{S}}\right)^{n_{S}}$, can also be expressed as 


$$
q_{e}=\frac{q_{m} C_{e}^{n_{s}}}{a+C_{e}^{n_{S}}}
$$

where $q_{\mathrm{e}}$ is the adsorbed amount at equilibrium $\left(\mathrm{mg} \mathrm{g}^{-1}\right), C_{\mathrm{e}}$ the equilibrium concentration of the adsorbate $\left(\mathrm{mg} \mathrm{L}^{-1}\right), q_{m s}$ the Sips maximum adsorption capacity $\left(\mathrm{mmol} \mathrm{g}^{-1}\right), K_{\mathrm{S}}$ the Sips equilibrium constant $\left(\mathrm{L} \mathrm{mg}^{-1}\right)$, and $n_{\mathrm{S}}$ the Sips model exponent describing heterogeneity. If the value of $K_{\mathrm{S}}$ approaches 0 (when value of $a$ approaches to infinity), the Sips isotherm will become a Freundlich isotherm. While the value of $n_{\mathrm{s}}=1$ or closer to 1 , the Sips isotherm Eq. reduces to the Langmuir Eq.; that is, adsorption takes place on homogeneous surface [21, 32].

At low adsorbate concentrations, the Sips isotherm effectively reduces to the Freundlich isotherm and thus does not obey the Henry's law. At high adsorbate concentrations, it predicts a monolayer adsorption capacity, characteristic of the Langmuir isotherm.

\section{Redlich-Peterson isotherm}

The Redlich-Peterson isotherm [35], contains three parameters, $A_{R P}, B_{R P}$ and g, and the form of the Eq. includes features of the Langmuir and Freundlich isotherms. This isotherm is represented by:

$$
q_{e}=\frac{A_{R P} C_{e}}{1+B_{R P} C_{e}^{g}}
$$


where $q_{e}\left(\mathrm{mg} \mathrm{g}^{-1}\right)$ is the solid-phase sorbate concentration at equilibrium, $\mathrm{C}_{e}\left(\mathrm{mg} \mathrm{L}^{-1}\right)$ is the concentration of adsorbate in equilibrium with liquid phase, $A_{R P}\left(\mathrm{~L} \mathrm{~g}^{-1}\right)$ and $B_{R P}(\mathrm{~L}$

$\mathrm{mol}^{-1}$ ) are the Redlich-Peterson isotherm constants, while $g$ is the exponent, which lies between 0 and 1. When exponent $g=0$, Eq. (18) transforms to Henry`s law equation. For exponent $g=1$, Eq. (18) converts to the Langmuir form [33].

\section{Toth isotherm}

The Toth isotherm is an empirical model, which was developed to yield an improved fit versus traditional Langmuir isotherm modelling $[21,23]$. It is often useful in the case for describing heterogeneous systems. The Toth isotherm model approaches the Henry region at infinite dilution.

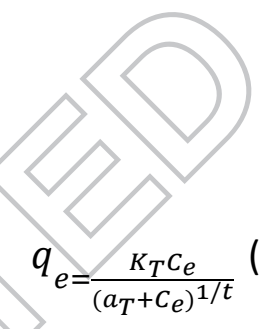

where $a_{\mathrm{T}}$ is adsorptive potential constant $\left(\mathrm{mg} \mathrm{L}^{-1}\right)$ and $K_{\mathrm{T}}$ Toth's heterogeneity factor.

\subsubsection{Error functions}

Various measures for model error, or error functions, have been developed through the decades of research on mathematical modeling. A simple and natural way to measure error 
of a model is to calculate differences from comparable pairs of observed and modeled values, and to add the absolute values of the differences together. Even better measure for the model error is obtained if the differences are squared. The sum of squared errors (SSE), is the most commonly used measure for model error, and is defined as

$$
S S E=\sum_{i=1}^{n}\left(x_{i, \text { calc }}-x_{i, \text { meas }}\right)^{2}
$$

where $x_{i, \text { meas }}, i=1, \ldots n$, are the measured values and $x_{i, \text { calc }}, i=1, \ldots$ the corresponding calculated values. In this study, SSE and other error functions are applied to the equilibrium concentrations, when $x_{i, \text { meas }}=q_{e, i, \text { meas }}$ and $x_{i, \text { calc }}=q_{e, i, \text { calc }}$

When the spread of the values in the data set is large, as the case usually is with adsorption isotherms describing the system behavior both on very low and very high concentrations, optimizing model parameters by minimizing $S S E$ tends to lead to relatively better fit with high values. In the case of adsorption isotherm models this means bias towards high concentrations. To avoid this, it's possible to replace $S S E$ by some of the relative error functions. In error measures, such as average relative error (ARE) and chi-square error $\left(\mathrm{X}^{2}\right)$, the difference between observed and modelled value (squared or not) is considered as proportional, in respect to observed or modelled value [23, 36-38]. They are defined as

$$
A R E=\frac{100}{n} \sum_{i=1}^{n}\left|\frac{x_{i, \text { calc }}-x_{i, \text { meas }}}{x_{i, \text { meas }}}\right|
$$

and

$$
\mathrm{X}^{2}=\sum_{i=1}^{n} \frac{\left(x_{i, \text { calc }}-x_{i, \text { meas }}\right)^{2}}{x_{i, \text { calc }}}
$$


Chi-square error can be developed to consider also model complexity. Reduced chi-square error is defined as

$\mathrm{X}_{\mathrm{red}}^{2}=\frac{1}{K} \sum_{i=1}^{n} \frac{\left(x_{i, \text { calc }}-x_{i, \text { meas }}\right)^{2}}{x_{i, \text { calc }}}$

where $K$ denotes degrees of freedom. If the number of parameters in a linear model is $p$ and number of observations is $n$, then $K=n-p$. In addition to fitting parameters, the reduced chi-square error can be also used to indicate if it is desirable or not to increase the number of parameters in the model, leading to greater model complexity. If this criterion is used, the model producing smaller reduced chi-square error is considered as the better one.

Hybrid fractional error is very similar to the reduced chi-square error, basically the difference being only the measured values as divisor instead of the calculated ones, additionally it's usually defined as scaled by factor 100 :

$$
\text { HYBRID }=\frac{100}{K} \sum_{i=1}^{n} \frac{\left(x_{i, \text { calc }}-x_{i, \text { meas }}\right)^{2}}{x_{i, \text { meas }}}
$$

Yet another error function considering degree of freedom, and used commonly in adsorption studies, is Marquardt's percent standard deviation (MPSD), defined as

$$
M P S D=\frac{100}{K} \sqrt{\sum_{i=1}^{n}\left(\frac{x_{i, \text { calc }}-x_{i, \text { meas }}}{x_{i, \text { meas }}}\right)^{2}}
$$


The error functions were applied to the commonly used isotherms models Langmuir, Sips, Freudlich, Toth and Redlich-Peterson. Andrae et al. recommended reduced chi-square not to be used for nonlinear models [39]. Despite that the reduced chi-square and similar error functions considering degree of freedom are widely applied to the nonlinear isotherm models listed above.

\section{Results and discussion}

\subsection{Characterization studies}

The functional groups on the surface of synthesized $\mathrm{CHA} / \mathrm{MFC}$ adsorbent were analyzed using Fourier Transform Infrared (FTIR) spectroscopy at wavelengths in the range 400-4000 $\mathrm{cm}^{-1}$. Fig. 1 shows the FT-IR spectra of unmodified MFC and CHA modified MFC. A weak band at around $3330 \mathrm{~cm}^{-1}$ is corresponding to hydroxyl stretching. There were two absorption peaks at $2900 \mathrm{~cm}^{-1}$ witch corresponding to the tension and vibration of $-\mathrm{CH}_{2}$ in both spectra. The few others characteristic peaks of unmodified MFC occurred in the spectra: the $\mathrm{CH}$ and $\mathrm{OCH}$ in-plane bending vibrations at around $1430 \mathrm{~cm}^{-1}$, the $\mathrm{CH}$ deformation vibration at $1370 \mathrm{~cm}^{-1}$, the $\mathrm{C}=\mathrm{O}, \mathrm{C}=\mathrm{C}$, and $\mathrm{C}=\mathrm{H}$ deformation modes and stretching vibrations in which the motions of the C-5 and C- 6 atoms are at $895 \mathrm{~cm}^{-1}[19-21$, 40, 41$]$

The bending mode of $\mathrm{OH}-$ groups was found at around $1640 \mathrm{~cm}^{-1}$. The band at $600 \mathrm{~cm}^{-1}$ is caused by the liberation mode of the $\mathrm{O}-\mathrm{H}$ vibration in the $\mathrm{CHA} / \mathrm{MFC}$ spectra. The peaks at 
$960-1025 \mathrm{~cm}^{-1}$ and 560 to $645 \mathrm{~cm}^{-1}$ could be related to asymmetric and symmetric stretching vibrations of $\mathrm{PO}_{4}{ }^{3-}$, respectively. The peaks at $1420 \mathrm{~cm}^{-1}$ and $880 \mathrm{~cm}^{-1}$ is characteristic of the presence of $\mathrm{CO}_{3}{ }^{2-}[19-21,40,42]$.

Figure 1

The components of CHA/MFC composite material, determined by energy dispersive X-ray spectroscopy (EDX), contains O: 33.3 wt.\%, Na: 19.2 wt.\%, Ca: 16.1 wt.\%, C: 11.8 wt.\% P: 11.2 wt.\% and $\mathrm{Cl}: 1.3$ wt.\%. High concentrations of $\mathrm{Ca}$ and P indicate that MFC can bind to a much larger amount of $\mathrm{CHA}$ than its own mass. The results of elemental analysis also confirm these results (Table 1 ). $\mathrm{Cl}, \mathrm{Na}$ and $\mathrm{N}$ originate from the starting materials of synthesis; urea, $\mathrm{NaOH}, \mathrm{CaCl}_{2}$ and $\mathrm{NaH}_{2} \mathrm{PO}_{4}$.

SEM images of MFC and CHA/MFC nanocomposites are shown in Fig. 2a and b. Most of MFC fibers are 50-100 $\mu \mathrm{m}$ in diameter, however, the morphology of CHA/MFC has lost the fibrous structure and presents the irregular flakes (Fig. 2b). Furthermore, it is observed that the CHA nanocrystallites is homogeneously dispersed in the cellulose matrix. Due to the variety of hydroxyl groups of cellulose and $\mathrm{CHA}$, hydrogen bonds can be formed between the cellulose and $\mathrm{CHA}$, which make the combination of these two components perfect.

\section{Figure $2 \mathrm{a}$ and $\mathrm{b}$}

Table 1.

\subsection{Effect of pH}


As can be seen in Fig. 3, sulfate from both sources loadings in $\mathrm{CHA} / \mathrm{MFC}$ were increased as the solution $\mathrm{pH}$ increased until 7. The solution $\mathrm{pH}$ can significantly affect the surface charge. Highest adsorption of negatively-charged sulfates on $\mathrm{CHA} / \mathrm{MFC}$ at a pH 6.5-7 are observed in Fig. 3. The zeta potential was negative $(-18.5 \pm 1.5 \mathrm{mV})$ at these $\mathrm{pH}$ level, which indicates the negative surface charge. $\mathrm{CHA} / \mathrm{MFC}$ surface becomes negative due to neutral $=\mathrm{CaOH}$ in alkaline solutions and negatively charged $\equiv P O_{4}^{-}$species (" $\equiv "$ is the surface) $[19-21,42]$. There are also carboxyl and hydroxyl groups on the surface of MFC. In alkaline conditions, these groups are deprotonated and therefore, exhibit a negative character. The isoelectric point of $\mathrm{CHA} / \mathrm{MFC}$ was found to be at $\mathrm{pH} 2.80$ and below this, the surface charge was positive. The attractive forces between positively charged surface and negatively charged sulfate ions may enhanced the adsorption of sulfate onto the surface of $\mathrm{CHA}$ in the acidic conditions. As can be seen in Figure 3, sulfate concentration of the solution had no effect on the adsorption in the $\mathrm{pH}$ range of 2-9; the best sulfate removal was found at $\mathrm{pH} 7$.

As the Fig. 3 shows, the final $\mathrm{pH}$ was alkaline ( $\mathrm{pH}$ 6.8-7) regardless of the initial $\mathrm{pH}$ range 28. This outcome was explained by the $\mathrm{CHA} / \mathrm{MFC}$ has the neutralization and buffering properties. CHA has the buffering characteristics due to the acid-base reactions of the reactive surface sites. The surface properties of $\mathrm{CHA}$ in aqueous solutions caused the reactions below [19-21, 42]:

$$
\begin{aligned}
& \equiv \mathrm{PO}^{-}+\mathrm{H}^{+} \leftrightarrow \equiv \mathrm{HPO} \\
& \equiv \mathrm{CaOH}_{2}^{+} \leftrightarrow \equiv \mathrm{CaOH}+\mathrm{H}^{+}
\end{aligned}
$$


The protonation of surface $\equiv \mathrm{PO}^{-}$and $\equiv \mathrm{CaOH}$ groups caused the increase of final $\mathrm{pH}$ during the alkaline initial pH-values. In the acidic conditions, the positively charged $\equiv \mathrm{CaOH}_{2}^{+}$and neutral $\equiv \mathrm{POH}$ sites caused positively charge of the surface. In the alkaline pH conditions, decreasing of the final $\mathrm{pH}$ caused the deprotonation of surface $\equiv \mathrm{CaOH}_{2}^{+}$and $\equiv \mathrm{POH}$ sites. Under the circumstance, the surface of $\mathrm{CHA} / \mathrm{MFC}$ becomes negative due to neutral $\equiv \mathrm{CaOH}$ in alkaline solutions and negatively charged $\equiv \mathrm{PO}^{-}$species predominate in alkaline conditions $[19-21,42]$.

Figure 3

\subsection{Effect of contact time}

Adsorption is a physicochemical process that involves the mass transfer of adsorbate from the liquid phase to the adsorbent surface. A study of kinetics of adsorption is desirable as it provides information about the mechanism of adsorption, which is important to evaluate the efficiency of the process. Adsorption of sulfates from $\mathrm{Na}_{2} \mathrm{SO}_{4}$ and SLS on CHA/MFC was conducted as a function of time and the results are shown in Figure 4. The adsorption rate of sulfate sulfates from $\mathrm{Na}_{2} \mathrm{SO}_{4}$ and $\mathrm{SLS}$ was rapid: adsorption equilibrium achieved within the first $10 \mathrm{~min}$ for $120 \mathrm{mf} \mathrm{L}^{-1}$ solution. In case of $250 \mathrm{mg} \mathrm{L}^{-1}$ solutions the rate was even faster for both $\mathrm{Na}_{2} \mathrm{SO}_{4}$ and SLS solutions (Fig. 4). The experimental data of adsorption of sulfate and surfactant on cellulose particles have been analyzed by two different models viz. Lagergren's pseudo-first-order equation and pseudo-second-order equation.

As can be seen in Table 2 , the $\mathrm{R}^{2}$ value of the pseudo-first-order model was found to be lower than pseudo-second-order model for sulfate from both solutions. In case of SLS only, 
minor differences between models are noticed for $120 \mathrm{ppm}$ solutions. Based on these results, it is clear that the adsorption of sulfate of SLS on CHA/MFC did not follow the pseudo-first-order kinetic model for strong sulfate solutions (250 ppm). In case of $\mathrm{Na}_{2} \mathrm{SO}_{4}$ neither of the models does not describe absorption kinetics satisfactorily, but the same trend is seen in the case of SLS; the fit is better for $120 \mathrm{ppm}$ sulfate solutions. Based on the obtained correlation coefficients, pseudo-second-order fits better for sulfate adsorption than pseudo-first-order for modeling the adsorption kinetic of sulfate on CHA/MFC and the both models give better results in weaker solutions and slower adsorption rates. It is suggested that the chemical sorption is as the rate-limiting step of the adsorption mechanism and no involvement of a mass transfer in solution $[27,40]$.

\section{Figure 4.}

\section{Table 2.}

\subsection{Adsorption isotherms}

The equilibrium adsorption isotherms for the adsorption of $\mathrm{SLS}$ and $\mathrm{Na}_{2} \mathrm{SO}_{4}$ on the $\mathrm{CHA} / \mathrm{MFC}$ at $25{ }^{\circ} \mathrm{C}$ and $\mathrm{pH} 6$ were investigated. Table 3, Table 4 and Figure 5 present the results of modeling the experimental adsorption data of sulfur ions through nonlinear regression analysis for the four adsorption isotherms: Langmuir, Freundlich, Sips, Redlich-Peterson and Toth.

For SLS, the $\mathrm{R}^{2}$ values (or SSE error) of the isotherm plots indicate that the isotherm data fits to the models in the order Sips $>$ Redlich-Peterson $>$ Langmuir $>$ Toth $>$ Freundlich. The $\mathrm{R}^{2}$ 
values for different error functions and isotherm models are presented in Table 5. Albeit the adsorption capacity of sulfates on CHA/MFC were relatively high $\left(q_{e}=34.52 \mathrm{mg} \mathrm{g}^{-1}, q_{m}\right.$, Sips $=26.4 \mathrm{mg} \mathrm{g}^{-1}$ for SSE) (Table 6) the fitting results were poor for all error functions (Table 3 and 6). The reason of the poor fitting results of SLS may be the unequal adsorption on the surface of $\mathrm{CHA} / \mathrm{MFC}$ due to the foaming property of surfactants like SLS. The electrostatic interactions play an important role in the adsorption of surfactant, like anionic SLS, at the solid-liquid interface. The surface of $\mathrm{CHA} / \mathrm{MFC}$ are negatively charged under the occurring conditions. The anionic SLS will experience a repulsive electrostatic interaction with the negatively charged which can explain the unequal adsorption and poor fitting results.

If using the usual choice of error function, $\mathrm{SSE}$, or $\mathrm{R}^{2}$ values, the experimental data of $\mathrm{Na}_{2} \mathrm{SO}_{4}$ yielded fit in the following order: Toth $>$ Redlich-Peterson $>$ Sips $>$ Freundlich $>$ Langmuir. Toth isotherm was able to describe the adsorption equilibrium data a bit better than the other, but the differences were small between different models. It can be assumed that Toth isotherm fitted better than the others probably due to the heterogeneous distribution of the available active sites onto surface of CHA/MFC. This approach is also supported by Sips model.

The Sips isotherm constant, $n$, can be used as an estimation of the heterogeneity of the adsorption system, as this isotherm is a combination of Langmuir and Freundlich isotherms.

When $n$ equals unity, the Sips isotherm returns to the Langmuir isotherm and predicts homogeneous adsorption. On the other hand, deviation of $n$ value from the unity indicates heterogeneous surface. As shown in Table 3, the Sips isotherm constant deviated of the unity with sulfates of SLS in the all cases of error functions. On the other hand, the $q_{m}$ values 
of $\mathrm{Na}_{2} \mathrm{SO}_{4}$ (Table 4) as well as Figure $5 \mathrm{~b}$ indicates that the Langmuir model fits better with experimental data, which represents homogeneous adsorption in case of $\mathrm{Na}_{2} \mathrm{SO}_{4}$.

The Freundlich parameters are detailed in Tables 3 and 4 . Values $n>1$ indicate positive cooperativity in binding of sulfate and a heterogeneous nature of adsorption. As the tables 4 6 and 7 shows, the value of $\mathrm{n}$ is dependent on the used error function. In case of SLS value of $\mathrm{n}$ varied on both sides of unity, but in the case of $\mathrm{Na}_{2} \mathrm{SO}_{4}$ value $\mathrm{n}>1$ with all error functions. The adsorption of SLS appear as lower energy adsorption processes than the adsorption of $\mathrm{Na}_{2} \mathrm{SO}_{4}$. In addition, the higher $\mathrm{n}$ values are associated with lower $\mathrm{k}_{\mathrm{F}}$ values and a better fitting of the model with the experimental values.

In fact, the CHA/MFC presents a heterogeneous surface: adsorption properties are mainly because of the functional groups $\mathrm{Ca}^{2+}, \mathrm{PO}_{4}^{3-}$, and $\mathrm{OH}^{-}$, denoted $\equiv \mathrm{Ca}^{2+}, \equiv \mathrm{PO}_{4}^{3-}$, and $\equiv \mathrm{OH}^{-}$. The groups above are participated in the surface reactions [19-21, 42]. Depending on the solution conditions, some different sites can be formed on the CHA surface [19, 20, 42]:

$$
\begin{aligned}
& \equiv \mathrm{OH}^{-}+\mathrm{H}^{+} \leftrightarrow \equiv \mathrm{OH}_{2} \\
& \equiv \mathrm{PO}_{4}^{3-}+\mathrm{H}^{+} \leftrightarrow \equiv \mathrm{HPO}_{4}^{-} \\
& \equiv \mathrm{HPO}_{4}^{-}+\mathrm{H}^{+} \leftrightarrow \equiv \mathrm{H}_{2} \mathrm{PO}_{4} \\
& \equiv \mathrm{Ca}^{+}+\mathrm{OH}^{-} \leftrightarrow \equiv \mathrm{CaOH} \\
& \equiv \mathrm{PO}_{4}^{3-}+\mathrm{Ca}^{2+} \leftrightarrow \equiv \mathrm{PO}_{4} \mathrm{Ca} \\
& \equiv \mathrm{HPO}_{4}^{-}+\mathrm{Ca}^{2+} \leftrightarrow \equiv \mathrm{HPO}_{4} \mathrm{Ca}^{+}
\end{aligned}
$$


Adsorption capacities of various adsorbents towards sulfates as reported in literature are presented in Table 5. A comparison between this work and other reported data from the literature shows that $\mathrm{CHA} / \mathrm{MFC}$ is a potential adsorbent for sulfates removal.

Figure 5.

Table 3.

Table 5.

\subsection{Analysis of error functions}

There isn't any single measure to indisputably judge whether a model is good or not. Indeed, concept of goodness itself is hard or impossible to define uniquely, especially if considered various types of models. For example, if a simple model is replaced by a far more complicated model, which seems to give more accurate results when modeled values are compared to observations, is the new model certainly better? Answer to the question depends on the nature of the modeled phenomenon (models used should have some kind of theoretical justification), the properties of the models in comparison, the coverage and the quality of the observations available, and finally the purpose of the model, e.g. whether the model is to be used for extrapolation outside the range of observations or not.

\subsubsection{Analysis of SLS modeling}


When SLS data was modelled with the isotherm models, Sips model appeared to be the best one if the model error used in optimization was $S S E, \mathrm{X}^{2}, \mathrm{X}_{\text {red }}^{2}$ or HYBRID. When using MPSD, Freudlich appeared to be the best model, and Redlich-Peterson was the best when using $A R E$ (Table 6).

It's worth observing that Langmuir can be considered as a special case of Sips: if $n_{S}=1$, then Sips is reduced to Langmuir. Therefore, if optimal values for all parameters are found, Langmuir can be better than Sips only when using error functions considering degree of freedom, and thereby favoring simpler models. In this case, however, Sips was better than Langmuir also when using $\mathrm{X}_{\text {red }}^{2}$ and $H Y B R I D$, both considering the degree of freedom.

In the case of MPSD Langmuir was slightly better than Sips (Freundlich being the best one) but had very unrealistic value for the parameter indicating the maximum capacity. Optimal values for both parameters $q_{m}$ and $a$ were huge, practically leading to simple linear model. This is because with very large values of $a$ the expression of the Langmuir model can be approximated as

$$
q_{e}=\frac{q_{m} C_{e}^{n_{s}}}{a+C_{e}^{n_{s}}} \approx \frac{q_{m} C_{e}^{n_{s}}}{a}=k C_{e}^{n_{s}}
$$


where $k=\frac{q_{m}}{a}$ is a constant, thus it's linear model, and only ratio of parameters matters. When the parameters of Langmuir model with SLS data were optimized using MPSD as error function, Excel's Solver produced large values $q_{m} \approx 2.102 \cdot 10^{9}$ and $a \approx 2.923 \cdot 10^{10}$, when $k=\frac{q_{m}}{a} \approx 0.072$. The value of MPSD error was 19.89. Now, if value of $a$ is dropped to remarkably smaller (but still large) $1.00 \cdot 10^{6}$, and setting $q_{m}=k a=7.19 \cdot 10^{4}$, it can be seen that the value of MPSD error remains unchanged with accuracy of two decimal places. In this kind of unstable situation there are basically infinitely many different optimal parameter combinations, all of them probably unrealistic from practical point of view. A somewhat similar phenomenon was observed with Toth model when HYBRID was used: there were several parameter combinations producing practically equal total error. Possibly the strange and unrealistic behavior of certain models with certain error functions can be explained by irregularities in the experimental SLS values. Anything similar was not observed with $\mathrm{Na}_{2} \mathrm{SO}_{4}$ modeling.

Models were compared also using the coefficient of determination defined as

$$
R^{2}=1-\frac{\sum_{i=1}^{n}\left(x_{i, \text { calc }}-x_{i, \text { meas }}\right)^{2}}{\sum_{i=1}^{n}\left(x_{i, \text { meas }}-\bar{x}\right)^{2}}
$$

where $\bar{x}$ is the average of the measured values. Not surprisingly, the best results in the light of the coefficient of determination ( $R^{2}$ being closest to 1 ) were obtained when $S S E$ was Used as criteria. This happened with all isotherm models, and Sips had $R^{2}$ closest to 1 (the fact that Sips was the best one when using $S S E$ can be seen also in Table 6). The result can be easily explained by definitions of $R^{2}$ and $S S E$ :

$$
R^{2}=1-\frac{S S E}{\sum_{i=1}^{n}\left(x_{i, \text { meas }}-\bar{x}\right)^{2}}
$$


Obviously $R^{2}$ obtains it's maximum when $S S E$ is minimized, and therefore $R^{2}$ can't be considered as fair and unbiased criteria when trying to choose the best measure for isotherm model error. On the other hand, use of $A R E$ led to worst $R^{2}$ values. This result was well expected too, since $A R E$ is based on absolute errors instead of squared errors.

An interesting question is, which has greater effect on modeling results: the choice of error criteria, or the choice of isotherm model? This question was analyzed by calculating the ranges of modeled values, corresponding each experimental value, both in respect to choice of error measure and on the other hand in respect to choice of isotherm model. For example, when Langmuir model was used, the modeled value corresponding the highest concentration, $C_{e}=310.2 \mathrm{mg} \mathrm{L}^{-1}$ and experimental adsorption capacity $q_{e}=34.52 \mathrm{mg} \mathrm{g}^{-1}$, was variating between 16.69 ( $\mathrm{mg} \mathrm{g}^{-1}$, the result when $A R E$ was used) and 32.04 (the result when $\mathrm{X}^{2}$ or $\mathrm{X}_{\text {red }}^{2}$ was used), thus the magnitude of variation was $32.04-16.69 \approx 15.35$. When considering each data point, the average variation was between 9.08 and 15.55, depending on isotherm model. On the other hand, when the ranges were calculated from results obtained with different models, again taking the difference between the maximum and the minimum, the range of average variations was between 2.91 and 5.88 , depending on the error measure used. As a conclusion, it seems that choice of error measure had greater effect on the results than choice of model.

It's also worth observing that in general absolute errors of the models (absolute values of the differences between the experimental and the modeled values) were greater than the absolute difference between the models (comparison was done only using values based on 
parameters optimized with SSE error function). However, SIPS isotherm seemed to be an exception: it was differing from the other models more than from the experimental values. This is not a surprise considering the fact that Sips was judged as the best model with all error functions except MPSD and $A R E$.

\section{Table 6}

Figure 6

\subsubsection{Analysis of $\mathrm{Na}_{2} \mathrm{SO}_{4}$ modeling}

Generally, the models fitted the data better in the case of $\mathrm{Na}_{2} \mathrm{SO}_{4}$ than in the case of SLS.

Now Toth model was the best one if any of error functions $S S E, A R E$ and $\mathrm{X}^{2}$, not considering model complexity, was used. If using $\mathrm{X}_{\mathrm{red}}^{2}, H Y B R I D$ or $M P S D$, the simpler Freundlich model was judged as the best, Toth being punished of its increased number of parameters (7).

The variation of modelled values was remarkably smaller than with SLS, when different isotherm models and different error functions were used. Differently than with SLS, choice of error function and choice of model seemed to have effect of somewhat similar magnitude on the modeling results. The last result was similar but more distinct than with SLS: absolute errors of models were greater than differences between the models.

In the light of the results it seems that in the case of $\mathrm{Na}_{2} \mathrm{SO}_{4}$ it's not very crucial whatever of the commonly used isotherm models is chosen. It's also worth mentioning that choice of model should not be done solely based on the accuracy of the model (measured by any 
error function) in respect to the experimental values: it depends also on purpose of the modeling which model is the most appropriate to use.

\section{Table 7.}

\section{Figure 6.}

\subsection{Multi-component system adsorption}

The efficiency of the adsorbent in the removal of sulfates in the treatment of real wastewater like industrial or urban wastewaters is affected by the selectivity between various common chemical species. The adsorption in multi-component systems is complicated because ion-ion competition and ion-surface interactions are involved. The understanding of multi-component systems has proven to be intricate and it may be a result of one or all of the following parameters: ionic radius, electronegativity, the $\mathrm{pH}$ of the system, and the availability of the active sites on the adsorbent [43].

The effect of some anions namely, $\mathrm{NO}_{3}{ }^{-}, \mathrm{H}_{2} \mathrm{PO}_{4}$ and $\mathrm{NH}_{4} \mathrm{Cl}$ on $\mathrm{CHA} / \mathrm{MFC}$ was studied in multi-component system in the same experimental conditions of single-component systems. Selected ions are competed for the same adsorption sites with sulfates on the surface of CHA/MFC. The results show that the presence of other anions have no significant effect on anions adsorption capacity. The adsorption capacity for $\mathrm{Na}_{2} \mathrm{SO}_{4}$ was reduced to $13 \%$, and for SLS, adsorption capacity remained the same (Figure 7). This result can be explained by the specificity of CHA/MFC particles - anion interactions and there are also enough adsorption 
sites for all anions on the surface of $\mathrm{CHA} / \mathrm{MFC}$ due to minor competition between the ions occurred.

\section{Figure 7}

\section{Conclusions}

The adsorption of sulfates $\mathrm{Na}_{2} \mathrm{SO}_{4}$ of and SLS onto CHA/MFC from aqueous solutions was studied using CHA-MFC. Effect of the error function for the four adsorption isotherms: Langmuir, Freundlich, Sips, Redlich-Peterson and Toth was also studied. The results indicate that removal efficiency of $\mathrm{Na}_{2} \mathrm{SO}_{4}$ and $\mathrm{SLS}$ by $\mathrm{CHA} / \mathrm{MFC}$ is dependent on solution $\mathrm{pH}$, initial sulfate concentration, adsorbent mass and contact time. Results show that the Sips isotherm fit well with the equilibrium of adsorption on CHA/MFC surface. Maximum adsorption capacities were found to be $34.53 \mathrm{mg} \mathrm{g}^{-1}$ for sulfates of SLS and $7.35 \mathrm{mg} \mathrm{g}^{-1}$ for sulfates of $\mathrm{Na}_{2} \mathrm{SO}_{4}$. The pseudo-second order kinetics model fits better than pseudo-first order model for sulfate adsorption of $\mathrm{Na}_{2} \mathrm{SO}_{4}$. There were only minor differences between these two kinetic models in case of SLS. Based on the study of the effect of error function, it can be concluded that the using the various error functions is not always meaningful due to several error functions are very similar, and lead to approximately equal parameter values. However, the use of different error functions supports the knowledge that they give information about how sensitive the model parameters are for the criteria used to determine parameters, which is useful information when estimating the reliability of models.

\section{Acknowledgements}


Authors are grateful to Maa- ja vesitekniikan tuki ry (MVTT) for financial support.

\section{Reference}

[1] Zheng $\mathrm{Y}$, Yong $\mathrm{X}$, Yang $\mathrm{Z}-\mathrm{H}$, et al. The bacterial communities of bioelectrochemical systems associated with the sulfate removal under different pHs. Process Biochem. 2014; 49:1345-1351.

[2] Damaris G, Versiane AL. Batch and fixed-bed assessment of sulphate removal by the weak base ion exchange resin Amberlyst A21. J Hazard Mater. 2014; 280:209-215.

[3] Nadagouda MN, Pressman J, White C, et al. Novel thermally stable poly(vinyl chloride) composites for sulfate removal. J Hazard Mater.2011; 188: 19-25.

[3] WHO in: Guidelines for Drinking-Water Quality Genebra 2008 p. 668.

[4] USEPA in: Sulfate in Drinking Water U.S. Environmental Protection Agency Washington DC; 1999. Sepehr N, Yetilmezsoy K, Marofi S, et al. Synthesis of nanosheet layered double hydroxides at lower $\mathrm{pH}$ : Optimization of hardness and sulfate removal from drinking water samples. J Taiwan Inst Chem Eng. 2014; 25:2786-2800. 

aqueous solution using a modified natural zeolite with CTAB. Minerals Engineering. 2010; 23: 771-779.

[7] Bondi CAM, Marks JL, Wroblewski LB, et al. Human and Environmental Toxicity of Sodium Lauryl Sulfate (SLS): Evidence for Safe Use in Household Cleaning Products. Environ Health Insights. 2015; 9: 27-32.

Van der Bruggen B, Vandecasteele C. Removal of pollutants from surface water and groundwater by nanofiltration: overview of possible applications in the drinking water industry. Environ Pollut.2003; 122: 435-445.

[9] Fu L, Wang J, Su Y. Removal of low concentrations of hardness ions from aqueous solutions using electrodeionization process. Sep Purif Technol. 2009; 68: $390-396$.

Seo S-J, Jeon H, Lee J, et al. Investigation on removal of hardness ions by capacitive deionization (CDI) for water softening applications. Water Res. 2010; 44: 2267-2275. novel electrochemical seeds system. Desalin. 2010; 263: 285-289. 

organic matter and hardness. Water Res. 2010; 44: 2419-2430. by the weak baseion exchange resin Amberlyst A21. J Hazard Mater. 2014; 280: 209-215. Moret A, Rubio J. Sulphate and molybdate ions uptake by chitin-based shrimpshells. Mineral Engineering. 2003; 16: 715-722.

[15] Mulinari DR, da Silva MLCP. Adsorption of sulphate ions by modification ofsugarcane bagasse cellulose. Carbohydr Polym. 2008; 74: 617-620.

[16] Cao W, Dang Z, Zhou X-Q, et al. Removal ofsulphate from aqueous solution using modified rice straw: preparation charac-terization and adsorption performance. Carbohydr Polym. 2011; 85: 571-577.

Namasivayam C, Sangeetha D. Application of coconut coir pith for the removal of sulfate and other anions from water. Desalin. 2008; 219: 1-13. sulfate removal. J Hazard Mater. 2012; 221-222: 45-55. 
[19] Hokkanen S, Repo E, Johansson Westholm L, Lou S, Sainio T, Sillanpää M. Adsorption of $\mathrm{Ni}^{2+} \mathrm{Cd}^{2+} \mathrm{PO}_{4}{ }^{3-}$ and $\mathrm{NO}_{3}^{-}$from aqueous solutions by nanostructured microfibrillated cellulose modified with carbonated hydroxyapatite. Chem Eng J. 2014; 252: 64-74.

[20] Hokkanena S, Bhatnagar A, Repoa E, et al. 2016, Calcium hydroxyapatite microfibrillated cellulose composite as a potential adsorbent for the removal of $\mathrm{Cr}(\mathrm{VI})$ from aqueous solution, Chem Eng J.2013; 283: 445-452.

[21] Hokkanen,S, 2014, Modified nano- and microcellulose based adsorption materials in water treatment, Acta Universitatis, Lappeenrantaensis 588.

[22] He $M$, Chang $>C$, Peng $N$, et al. Structure and properties of hydroxyapatite/cellulose nanocomposite films. Carbohydr Polym. 2012; 87: $2512-2518$.

Foo KY, Hameed $\mathrm{BH}$, Insights into the modeling of adsorption isotherm systems. Review Chem Eng J. 2010; 156: 2-10.

[24]

Tien C, Ramarao BV, Further examination of the relationship between the Langmuir kinetics and the Lagergren and the second-order rate models of batch adsorption. Sep Purif Technol. 2014; 136: 303-308. 
Azizian S, Bashiri H. Adsorption kinetics at the solid/solution interface: statistical rate theory at initial times of adsorption and close to equilibrium. Langmuir. 2008; 24: 11669-11676.

[26] Tseng R-L, Wu P-H, Wu F-C, et al. A convenient method to determine kinetic parameters of adsorption processes by nonlinear regression of pseudo-nthorder equation. Chem Eng J. 2014; 237: 153-161.

[27] Ho Y-S. Second-order kinetic model for the sorption of cadmium onto tree fern: a comparison of linear and non-linear methods. Water Res. 2006; 40: 119-125.

[28] Freitas OMM, Martins RJE, Delerue-Matos CM, et al. Removal of Cd(II) Zn(II) and $\mathrm{Pb}(\mathrm{II})$ from aqueous solutions by brown marine macro algae: Kinetic modeling. J Hazard Mater. 2008; 153: 493-501.

[29] Ho YS, Ng JCY, McKay G. Kinetics of pollutant sorption by biosorbents: review. Sep Purif Methods. 2000; 29: 189-232.

Langmuir I. The constitution and fundamental properties of solids and liquids: Part I. J Am Chem Soc. 1916; 38: 2221-2295. 
Hokkanen S, Repo E, Lou S, et al. Removal of Arsenic(V) by Magnetic Nanoparticle Activated Microfibrillated Cellulose. Chem Eng J. 2015; 260: 886894. $385-471$.

Chatterjee S, Chatterjee T, Lim S-R, Woo Sh,(2011) Adsorption of a cationic dye, methylene blue, on to chitosan hydrogel beads generated by anionic surfactant gelation, Environ Technol.32:13, 1503-1514.

Hokkanen S, Repo E, Bhatnagar A, et al. Adsorption of hydrogen sulphide from aqueous solutions using modified nano/micro fibrillated cellulose. Environ Technol. 2014; 35: 2334-2346.

Redlich O, Peterson D L. A useful adsorption isotherm. J. Physic. Chem. 1959; 63: 1024 .

Allen SJ, Gan Q, Matthews R, Johnson PA. Comparison of optimized isotherm models forbasic dye adsorption by kudzu. Biores. Technol. 2003; 88: 143-152. 

Models for Acid Dyes onto Bamboo Derived Activated Carbon. Chin J Chem Eng. 2012; 20: 535-542. dye removal by cationized starch-based material in a single component system: Error analysis. J Hazard Mater. 2008; 157: 34-46.

[39] Andrae R, Schulze-Hartung T, Melchiorar P. 2010. Dos and don'ts of reduced chi-squared Xiv:1012,3754 [astro-ph,IM]

[40] Smiciklas I, Dimovic S, Plecas I, et al. Removal of Co2+ from aqueous solutions by hydroxyapatite. Water Res. 2006; 40: 2267-2274.

[41] Ghaneian MT, Ghanizadeh G, Alizadeh MTH, et al. Equilibrium and kinetics of phosphorous adsorption onto bone charcoal from aqueous solution. Environ Technol. 2014; 35:882-890. solution by carbonate hydroxylapatite derived from eggshell waste. J Hazard Mater. 2007; 147: 534-539. 

in enhanced oil recovery: Isotherms kinetics and thermodynamic studies. Appl Surf Sci. 2013; 284: 87- 99. sugarcane bagasse cellulose. Carbohydr Polym. 2008; 74: 617-620. nanofibers from waste pulp residues and their nitrate fluoride sulphate and phosphate adsorption properties. Carbohydrat Polym. 2016; 135: 334340. 


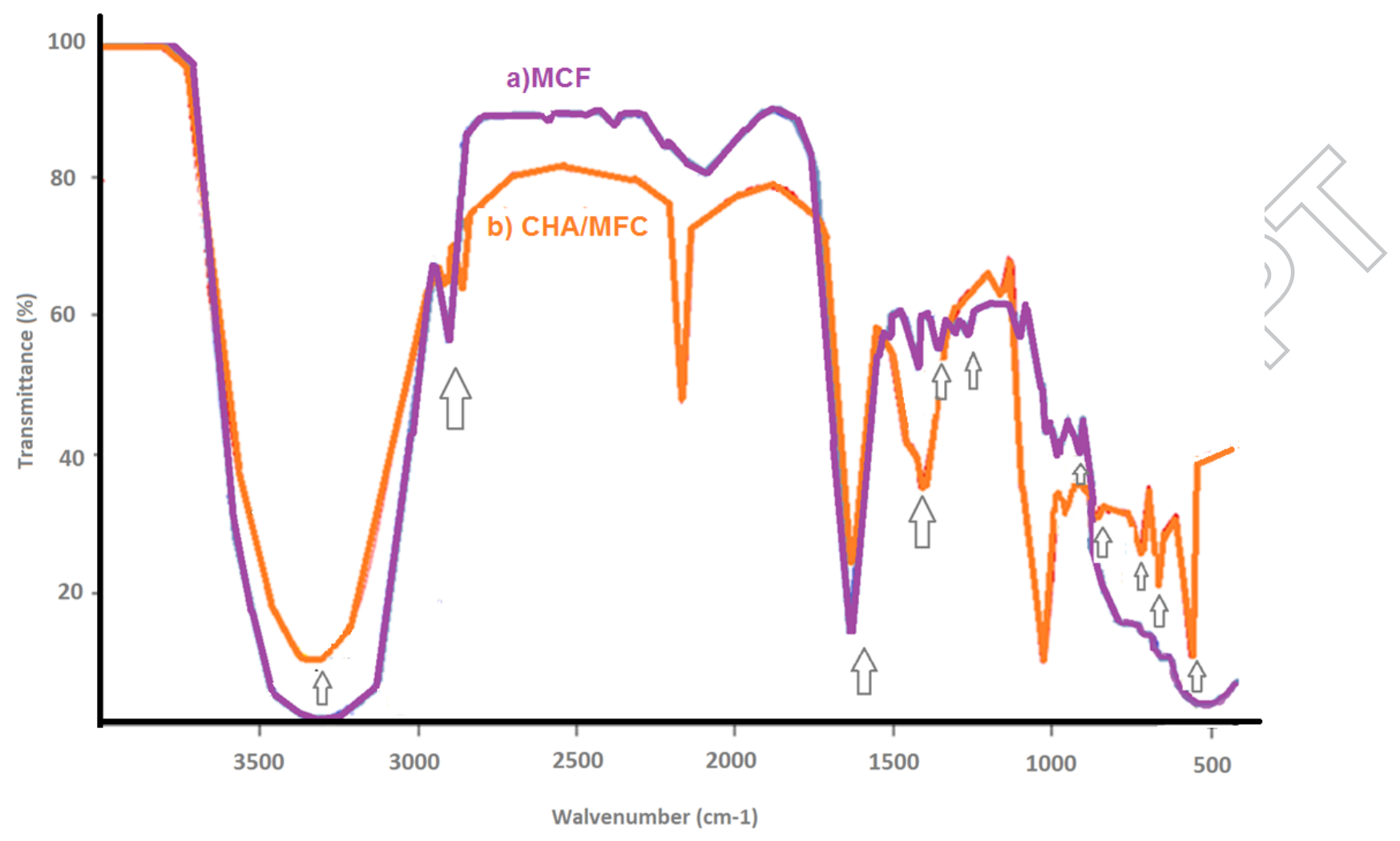

Fig. 1. FTIR-spectra of unmodified (a) and CHA modified MFC (b). 

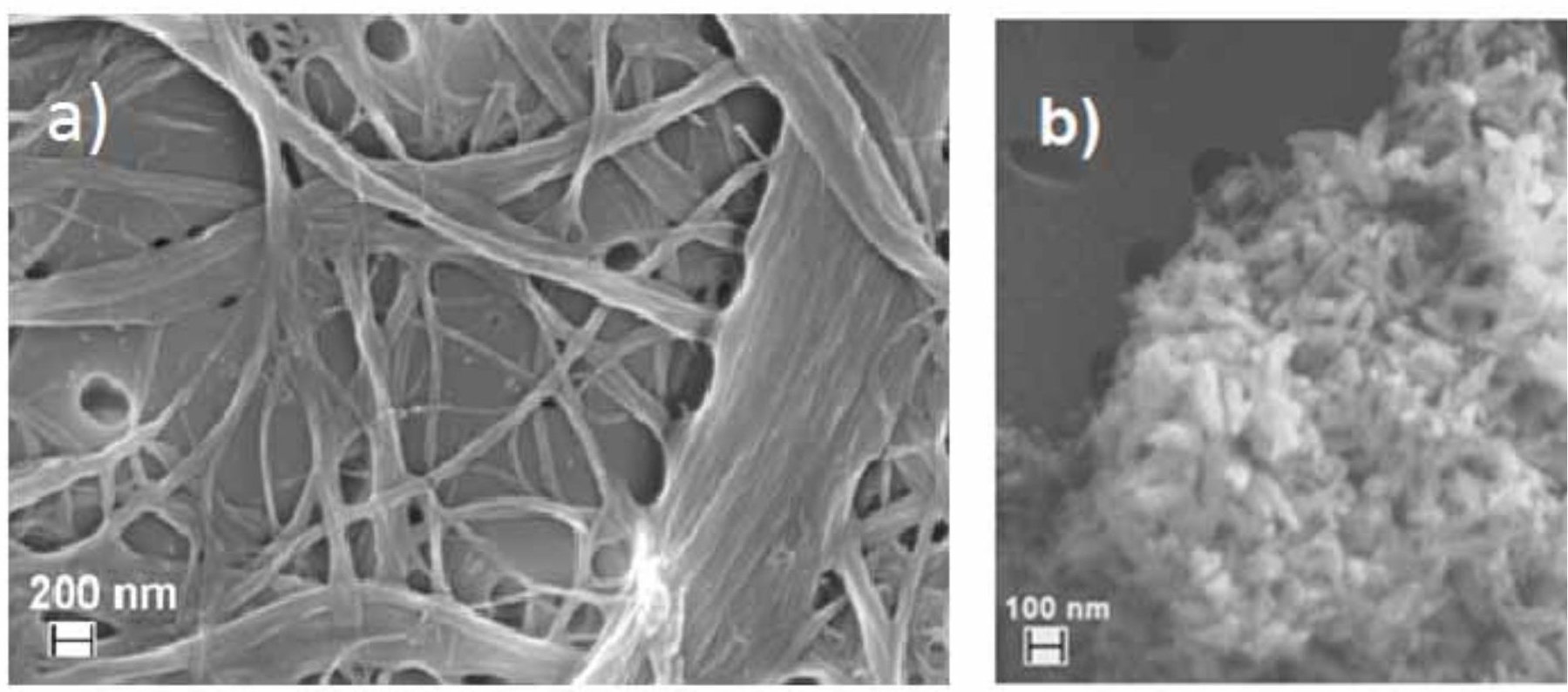

Fig. 2. SEM pictures of MFC (a) and CHA modifed MFC (b). 

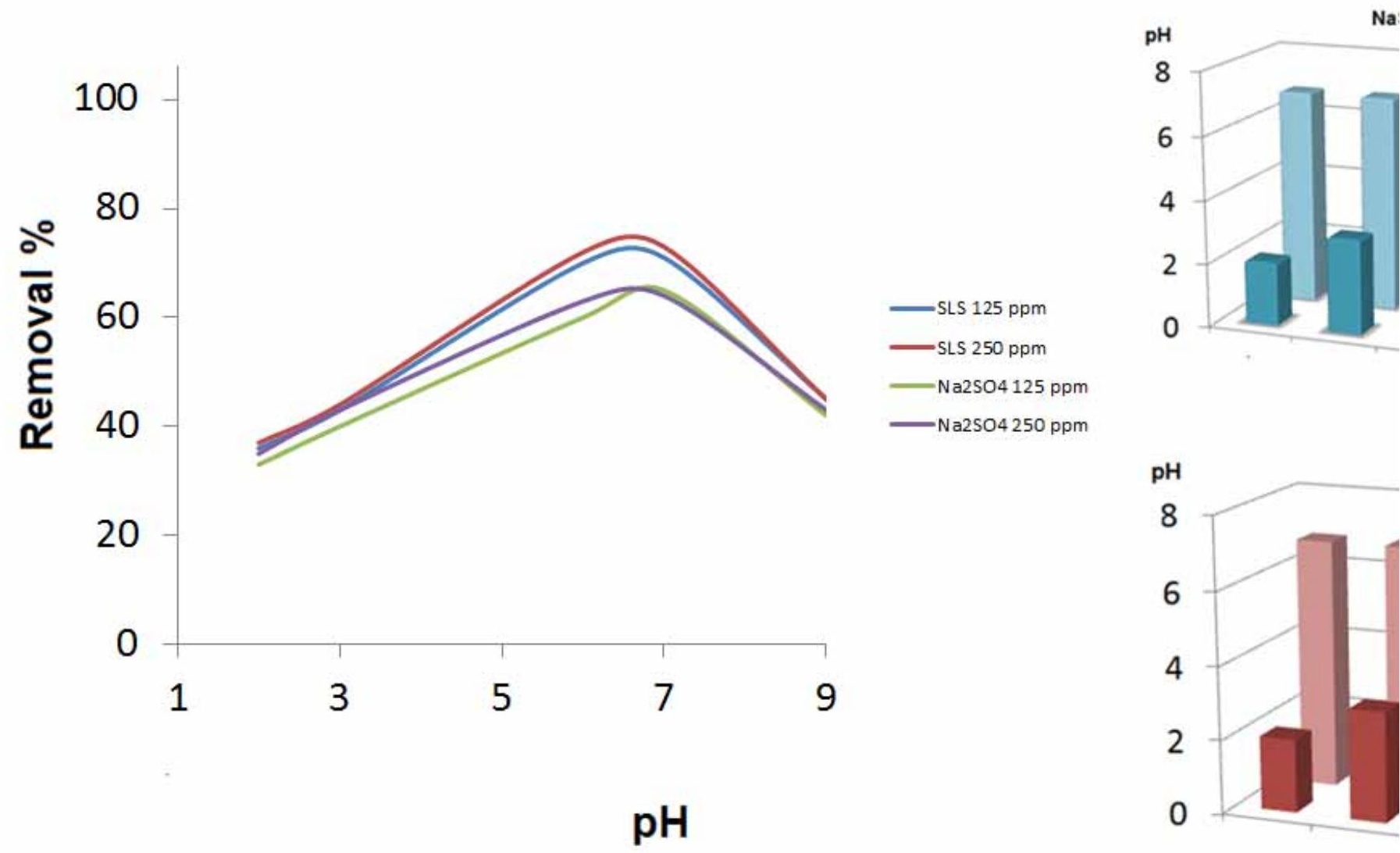

Fig. 3. Effect of $\mathrm{pH}$ for the adsorption. 


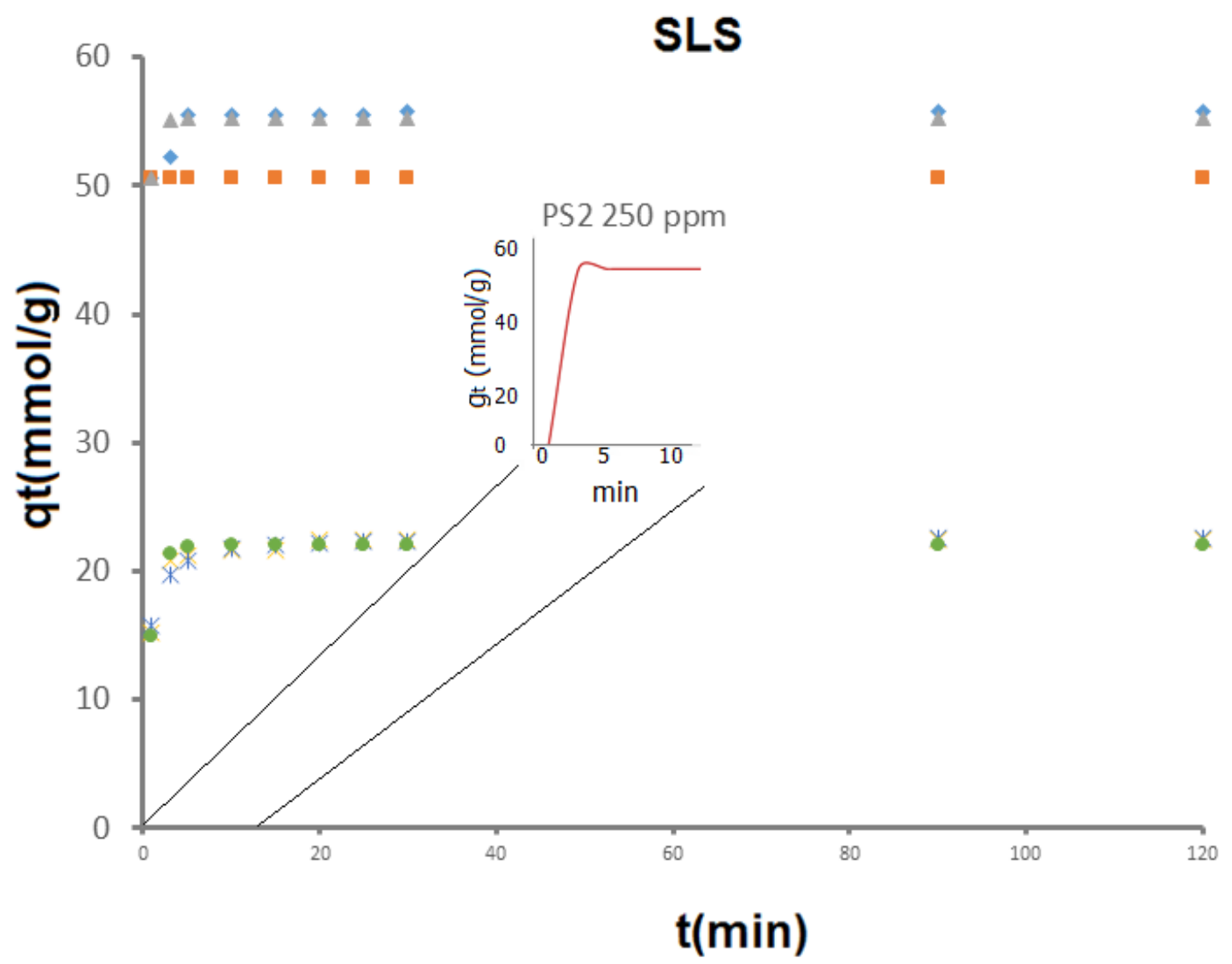

- EXP 250 ppm

- PS2 250 ppm

^ PS1 250 ppm

EXP 120 ppm

* PS2 120 ppm

- PS1120 ppm

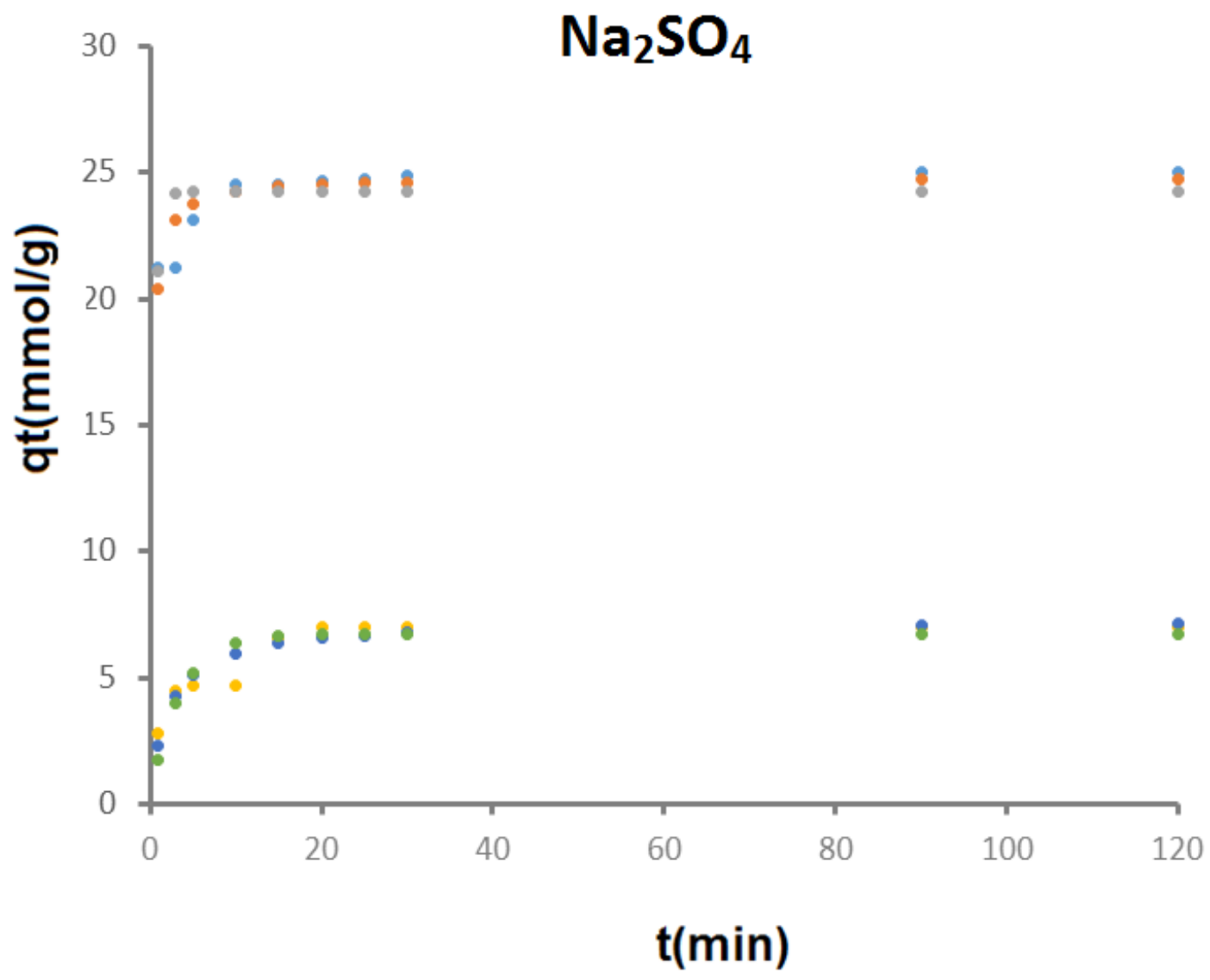

- EXP 120 ppm

- PS2 250 ppm

- PS1 250 ppm

- EXP 120 ppm

- PS2 120 ppm

- PS1 120 ppm 
Figure 4. Effects of contact time on $\mathrm{NaSO}_{4}$ and $\mathrm{SLS}$ adsorption by $\mathrm{CHA} / \mathrm{MFC}$ for solution concentrations of $120 \mathrm{ppm}$ and $250 \mathrm{ppm}$. EXP= experimental data; PS1=pseudo-first order model; PS2=pseudo-second order model. 


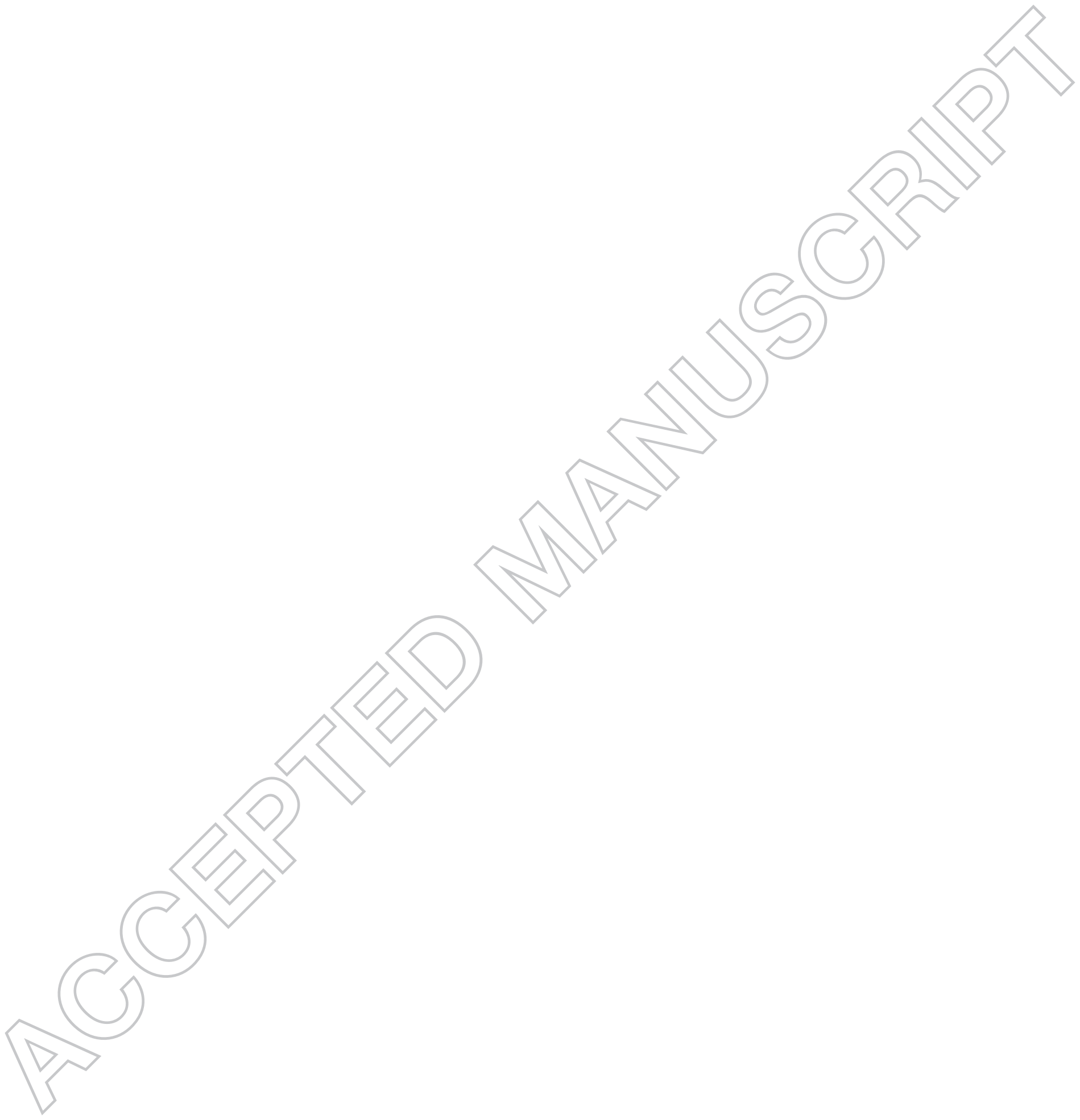


a)
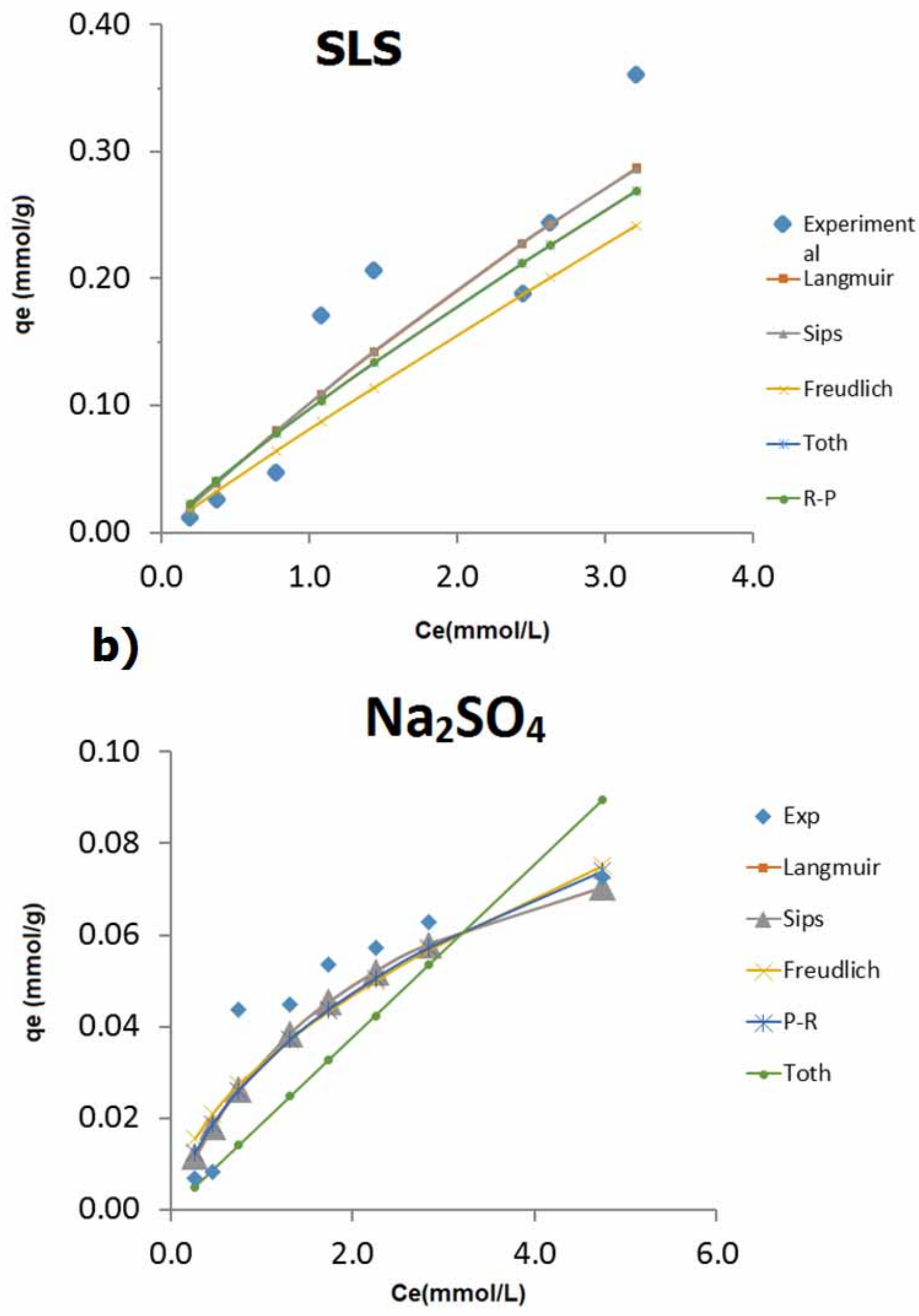
Fig. 5. Different isotherm models fitting for the adsorption of SLS and $\mathrm{Na}_{2} \mathrm{SO}_{4}$ on $\mathrm{CHA} / \mathrm{MFC}$. 

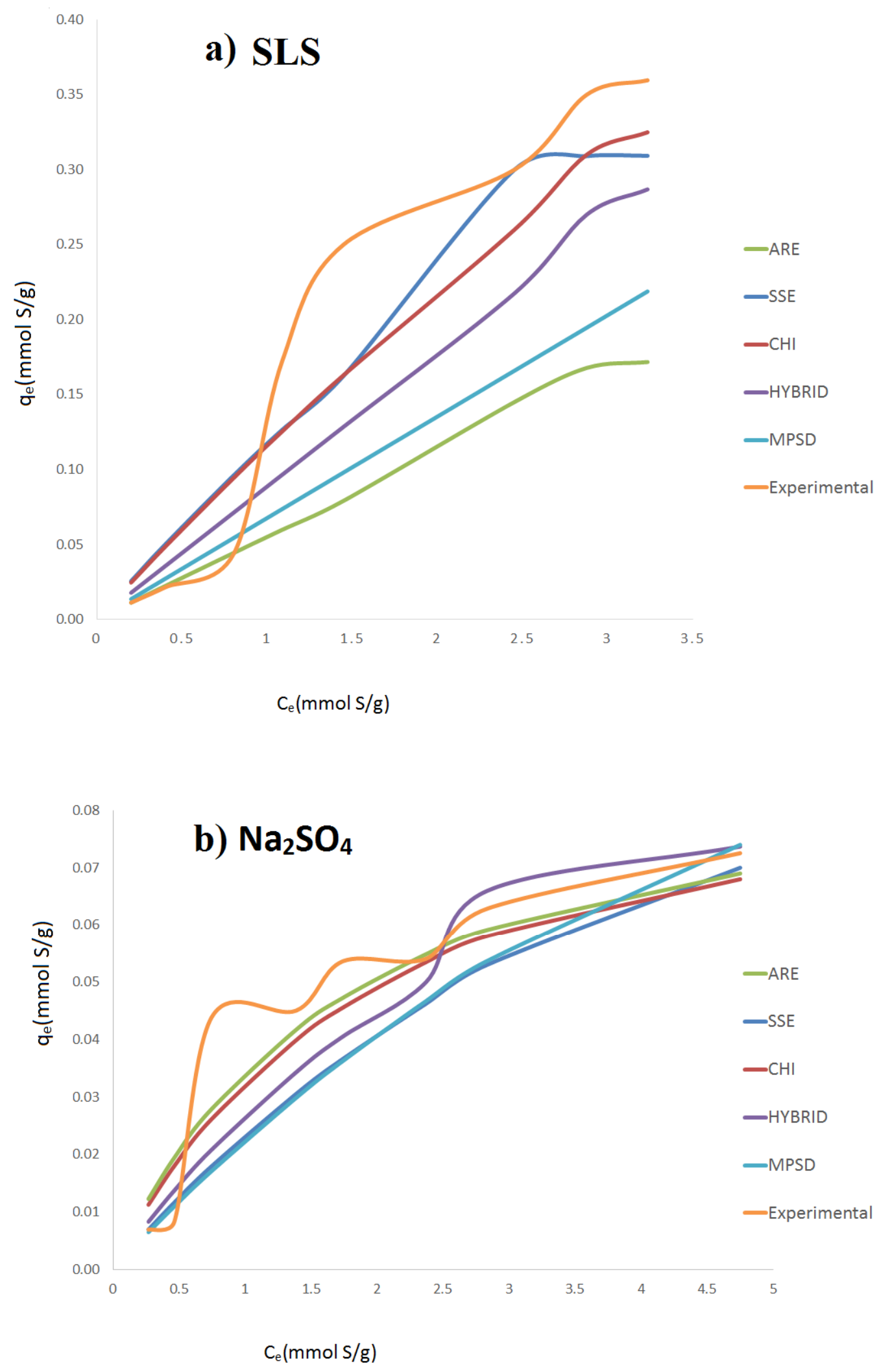

Figure 6. The effect of the error function on the Langmuir isotherm for a) SLS b) $\mathrm{Na}_{2} \mathrm{SO}_{4}$ adsorption by $\mathrm{CHA} / \mathrm{MFC}$. Dose: $16 \mathrm{~g} / \mathrm{L}, \mathrm{pH}: 5, \mathrm{SO}_{4}$ concentration: 0.9-15 mM. 


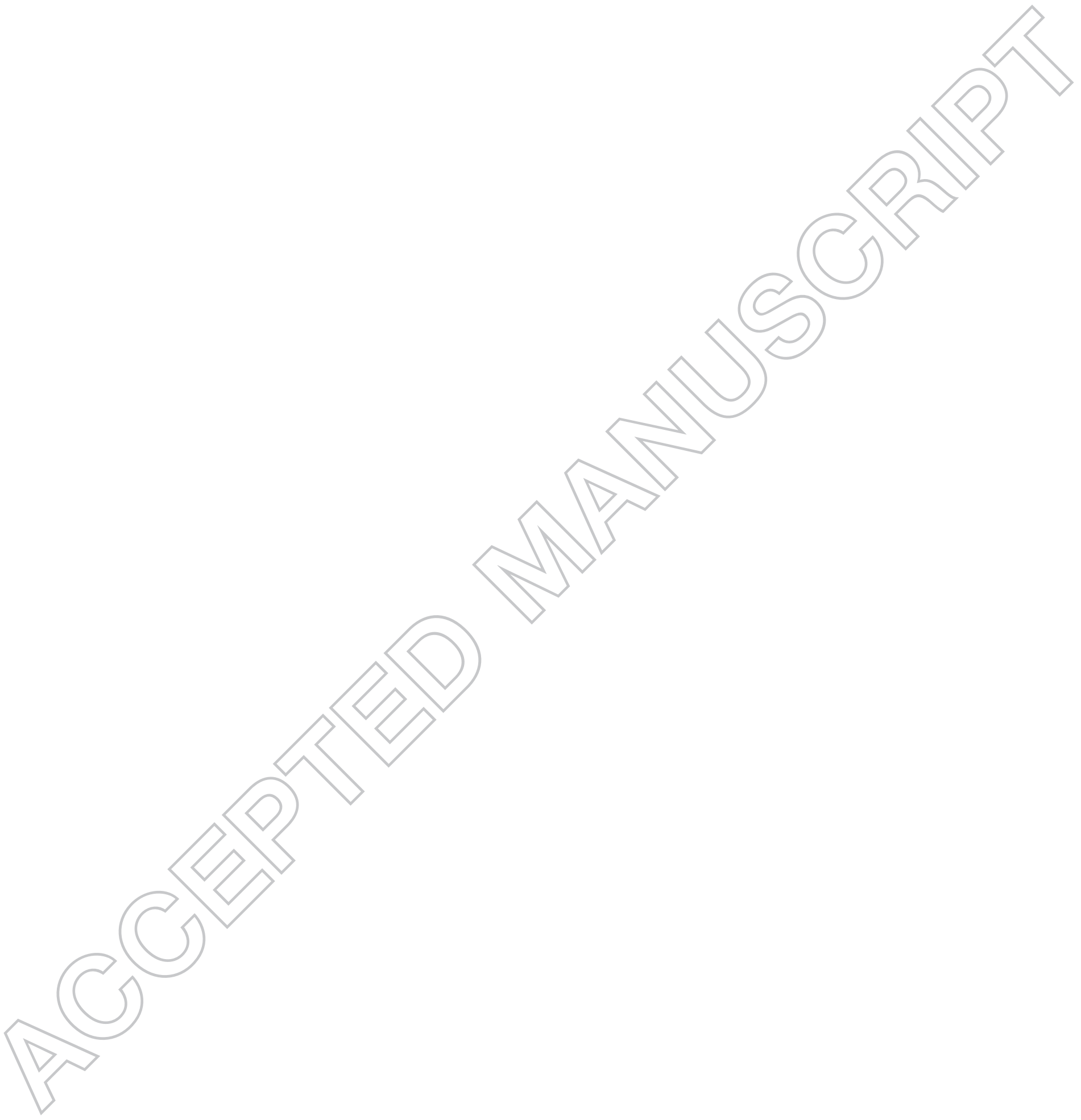




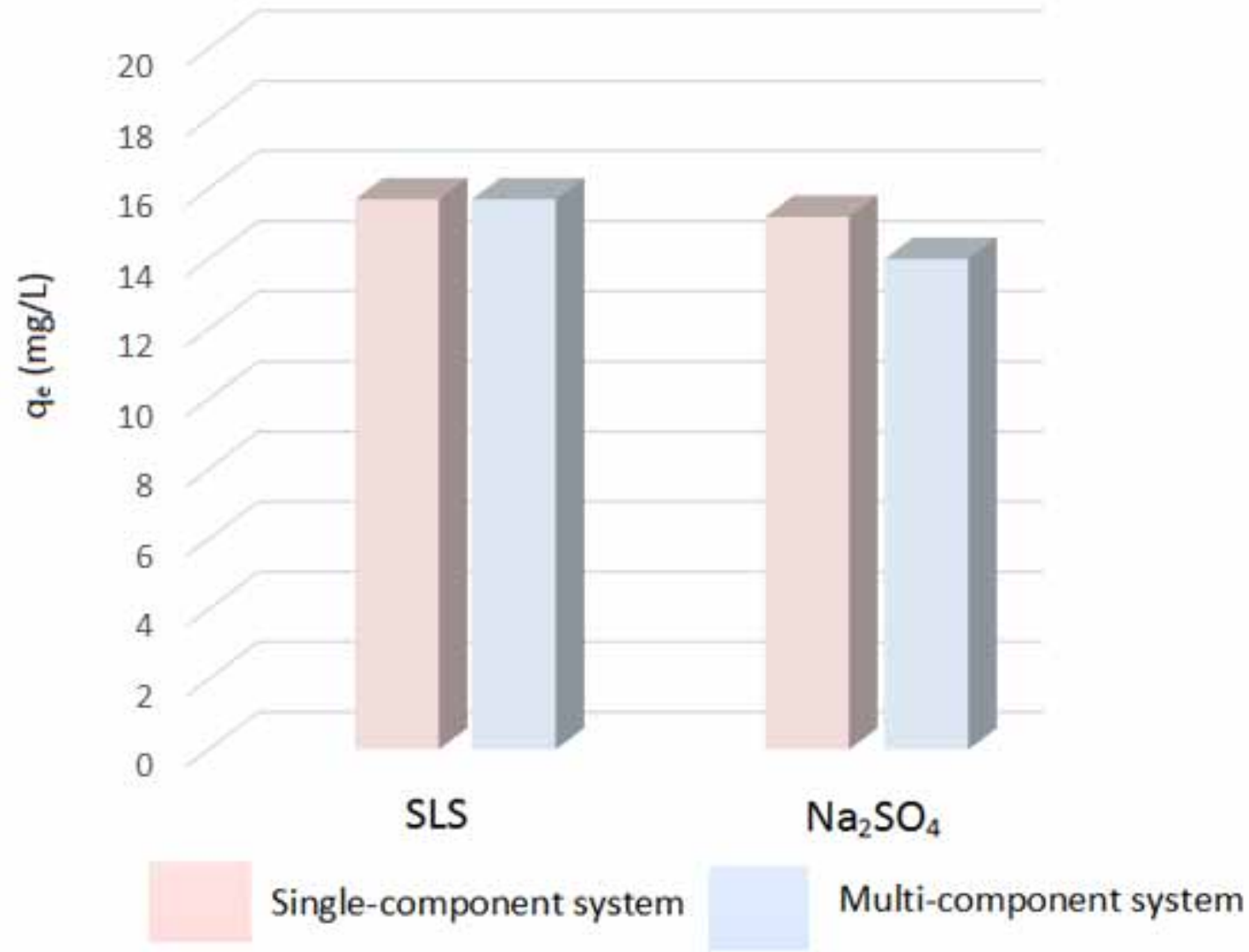

Figure 7. The effect of $\mathrm{NO}_{3}{ }^{-}, \mathrm{H}_{2} \mathrm{PO}_{4}$ and $\mathrm{NH}_{4} \mathrm{Cl}$ on adsorption of $\mathrm{SLS}$ and $\mathrm{Na}_{2} \mathrm{SO}_{4}$. Singlecomponent system $=\mathrm{SLS} / \mathrm{Na}_{2} \mathrm{SO}_{4}$ solution; multi-component-system $=\mathrm{NO}_{3}^{-}, \mathrm{H}_{2} \mathrm{PO}_{4}, \mathrm{NH}_{4} \mathrm{Cl}$ and SLS/ $/ \mathrm{Na}_{2} \mathrm{SO}_{4}$ in the same solution. Dose: $16 \mathrm{~g} \mathrm{~L}^{-1}, \mathrm{pH}: 7$, concentration: $200 \mathrm{mg} \mathrm{L}^{-1}$. 
Table 1. The elemental analysis results of unmodified and modified MFC.

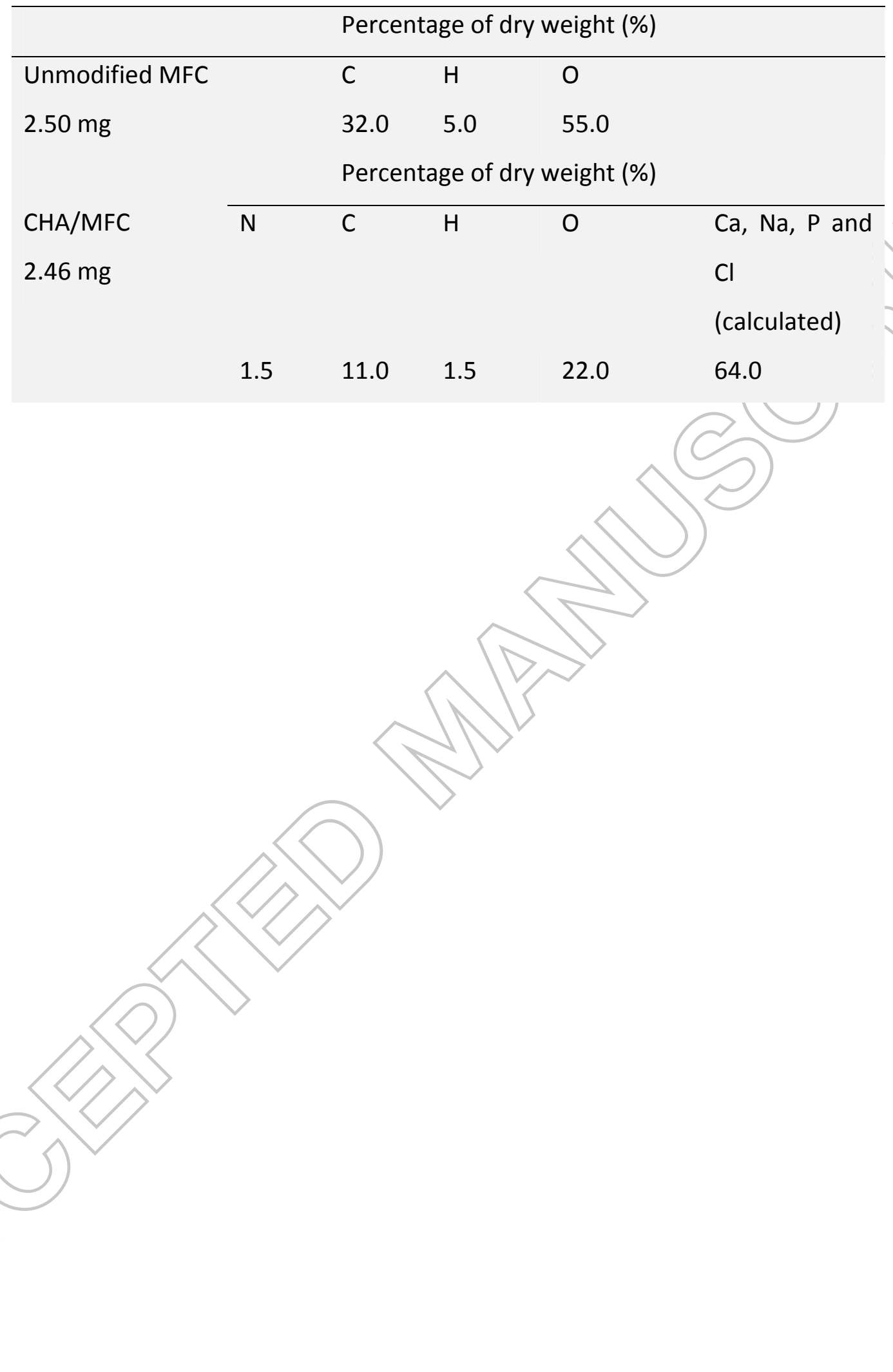


Table 2. Kinetics parameters for the adsorption of sulfates from $\mathrm{Na}_{2} \mathrm{SO}_{4}$ and $\mathrm{SLS}$ on CHA/MFC.

\begin{tabular}{|c|c|c|c|}
\hline Model & Parameter & Adsorbate & \\
\hline \multirow{6}{*}{ Pseudo-second-order } & & $\mathrm{SO}_{4} /\left(\mathrm{Na}_{2} \mathrm{SO}_{4}\right)$ & $\mathrm{SO}_{4} /(\mathrm{SLS})$ \\
\hline & $\mathrm{q}_{\mathrm{e}, \exp }(\mathrm{mg} / \mathrm{g})$ & 7.03 & 22.40 \\
\hline & $\mathrm{k}_{2}(\mathrm{~g} / \mathrm{mg} \min )$ & 0.07 & 0.10 \\
\hline & $\mathrm{q}_{\mathrm{e}, \mathrm{cal}}(\mathrm{mg} / \mathrm{g})$ & 7.25 & 22.70 \\
\hline & $\mathrm{h}(\mathrm{mg} / \mathrm{g} \min )$ & 3.24 & 51.21 \\
\hline & $R^{2}$ & 0.87 & 0.96 \\
\hline \multirow[t]{4}{*}{ Pseudo-first-order } & $\mathrm{k}_{1}(\mathrm{~g} / \mathrm{mg} \min )$ & 0.29 & 1.13 \\
\hline & $\mathrm{q}_{\mathrm{e}, \mathrm{cal}}(\mathrm{mg} / \mathrm{g})$ & 6.73 & 22.05 \\
\hline & $\mathrm{h}(\mathrm{mg} / \mathrm{g} \mathrm{min})$ & 13.46 & 550.40 \\
\hline & $\mathrm{R}^{2}$ & 0.76 & 0.95 \\
\hline
\end{tabular}




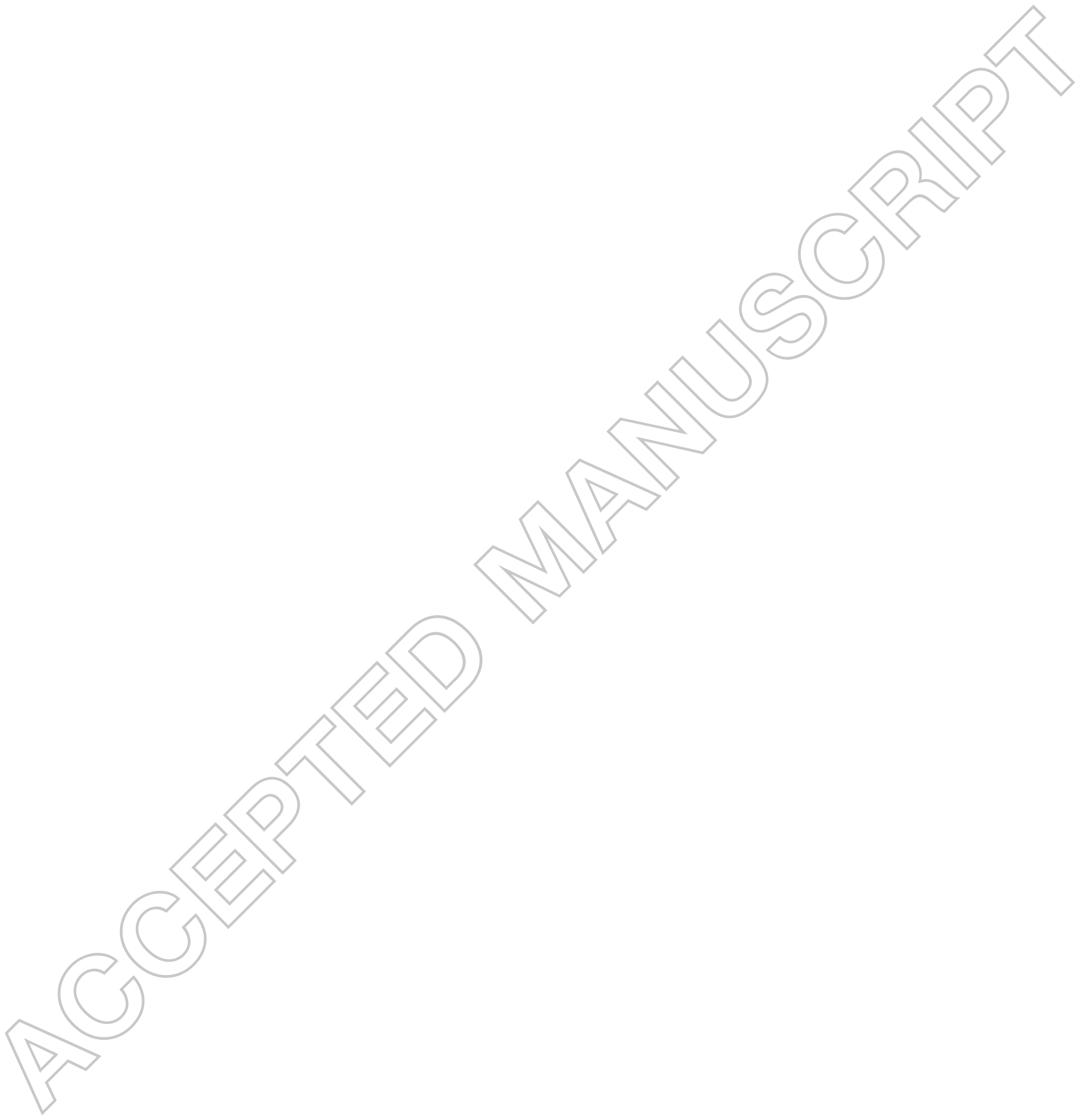


Table 3. Optimal parameter values, when different error functions were used for sulfate ions of SLS.

$\operatorname{SLS}\left(\mathbf{q}_{\text {exp. }}=34.5 \mathrm{mg} / \mathrm{g}\right)$

\begin{tabular}{llllll}
\hline & Langmuir & Sips & Freundlich & Toth & $\mathrm{R}-\mathrm{P}$ \\
\cline { 2 - 4 } & $\mathrm{q}_{\mathrm{m}}=61.3$ & $\mathrm{q}_{\mathrm{m}}=26.4$ & $\mathrm{k}=0.467$ & $\mathrm{~K}_{\mathrm{T}}=18.4$ & $\mathrm{~A}=0.163$ \\
& $\mathrm{a}=328.0$ & $\mathrm{a}=5.49 * 10^{13}$ & $\mathrm{n}=1.37$ & $\mathrm{a}_{\mathrm{r}}=251.3$ & $\mathrm{~B}=3.35^{*} 10^{-}$
\end{tabular}

* Not rational result 
Table 4. Optimal parameter values, when different error functions were used sulfate ions of $\mathrm{Na}_{2} \mathrm{SO}_{4}$.

\begin{tabular}{|c|c|c|c|c|c|}
\hline \multicolumn{6}{|c|}{$\mathrm{Na}_{2} \mathrm{SO}_{4}\left(\mathrm{q}_{\mathrm{e}, \exp .}=7.34 \mathrm{mg} / \mathrm{g}\right)$} \\
\hline & Langmuir & Sips & Freundlich & Toth & R-P \\
\hline \multirow[t]{3}{*}{ SSE } & $q_{m}=6.67$ & $q_{m}=9.89$ & $k=2.11$ & $\mathrm{~K}_{\mathrm{T}}=2.94$ & $A=1.33$ \\
\hline & $a=12.5$ & $a=5.77$ & $n=4.91$ & $a_{r}=3.54$ & $B=0.445$ \\
\hline & & $\mathrm{n}=0.435$ & & $t=1.17$ & $g=0.856$ \\
\hline \multirow[t]{3}{*}{ ARE } & $q_{m}=6.65$ & $q_{m}=55.2$ & $k=1.48$ & $\mathrm{~K}_{\mathrm{T}}=1.72$ & $A=1.43$ \\
\hline & $a=13.4$ & $a=34.3$ & $n=3.85$ & $a_{r}=1.08$ & $B=0.656$ \\
\hline & & $n=0.266$ & & $t=1.31$ & $g=0.807$ \\
\hline \multirow[t]{3}{*}{$\mathrm{X}^{2} / \mathrm{X}_{\mathrm{red}}^{2}$} & $q_{m}=6.69$ & $\mathrm{q}_{\mathrm{m}}=8.98$ & $k=2.09$ & $\mathrm{~K}_{\mathrm{T}}=3.31$ & $A=1.03$ \\
\hline & $a=11.8$ & $a=5.54$ & $n=4.84$ & $a_{r}=4.59$ & $B=0.294$ \\
\hline & & $n=0.487$ & & $t=1.14$ & $g=0.884$ \\
\hline \multirow[t]{3}{*}{ HYBRID } & $q_{m}=6.52$ & $q_{m}=10.6$ & $k=1.92$ & $\mathrm{~K}_{\mathrm{T}}=2.76$ & $A=1.24$ \\
\hline & $a=12.0$ & $a=6.36$ & $n=4.56$ & $a_{r}=3.45$ & $B=0.426$ \\
\hline & & $\mathrm{n}=0.413$ & & $t=1.18$ & $g=0.853$ \\
\hline \multirow[t]{3}{*}{ MPSD } & $q_{m}=6.36$ & $q_{m}=10.6$ & $k=1.78$ & $\mathrm{~K}_{\mathrm{T}}=2.72$ & $A=1.13$ \\
\hline & $a=11.6$ & $a=6.72$ & $n=4.30$ & $a_{r}=3.73$ & $B=0.392$ \\
\hline & & $n=0.422$ & & $t=1.18$ & $g=0.853$ \\
\hline
\end{tabular}




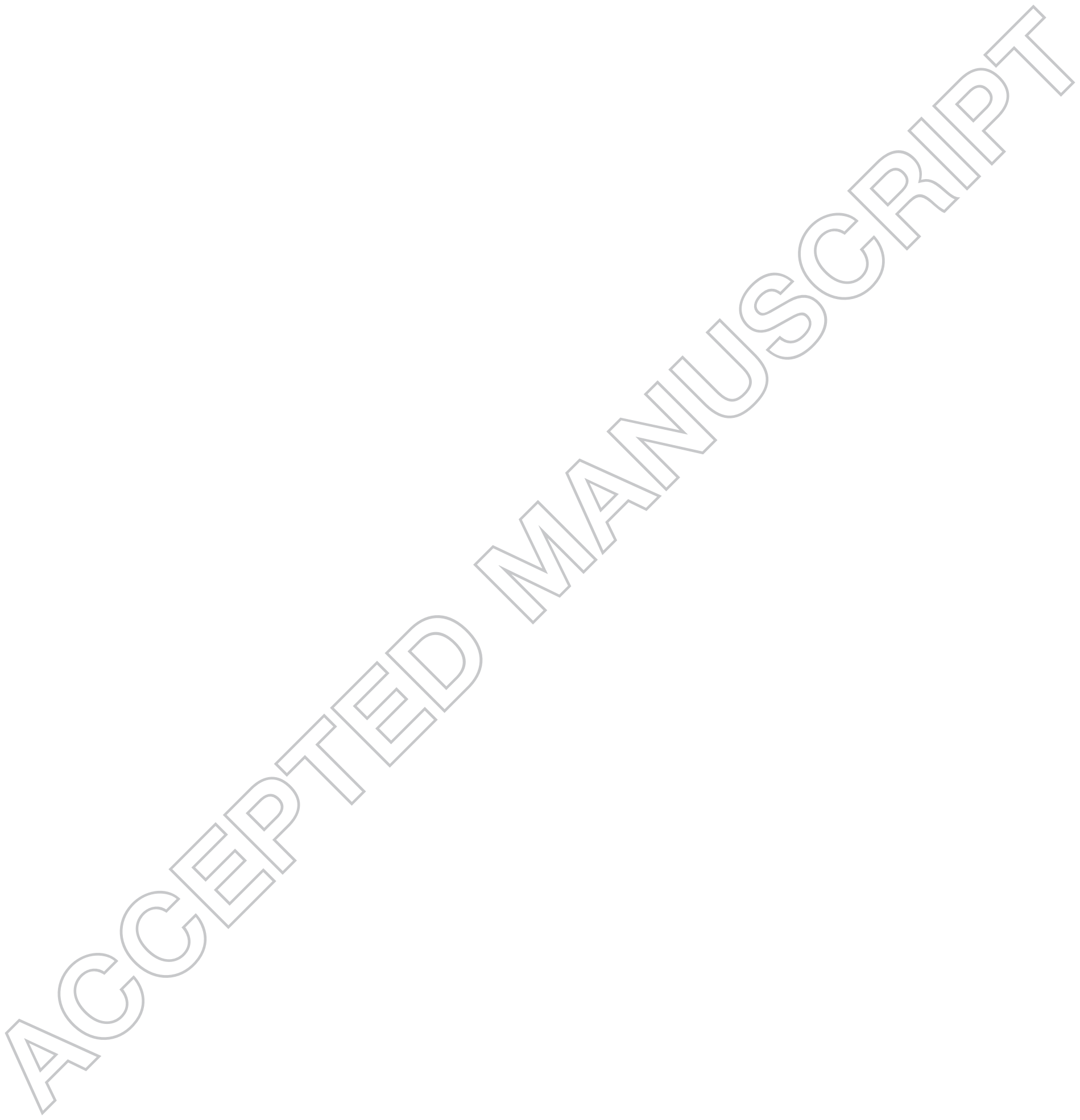


Table 5. A comparison between this work and other reported data from the literature for removal of sulfate from water.

\begin{tabular}{|c|c|c|c|}
\hline Adsorbent & Adsorbate & $q_{\max }(\mathrm{mg} / \mathrm{g})$ & \\
\hline Raw rice straw & $\mathrm{SO}_{4}^{-2}$ & $\begin{array}{l}11.68 \\
\text { (Langmuir) }\end{array}$ & [16] \\
\hline $\begin{array}{l}\text { Rice straw- Anion } \\
\text { Exchanger }\end{array}$ & $\mathrm{SO}_{4}^{-2}$ & $\begin{array}{l}74.76 \\
\text { (Langmuir) }\end{array}$ & [16] \\
\hline Sand surface & surfactants & $\begin{array}{l}1.03 \\
\text { (Langmuir) }\end{array}$ & [43] \\
\hline $\begin{array}{l}\text { Sugarcane bagasse cellulose with } \\
\text { zirconium oxychloride }\end{array}$ & $\mathrm{SO}_{4}^{-2}$ & 32.06 & [44] \\
\hline Cationic cellulose nanofibers & $\mathrm{SO}_{4}^{-2}$ & 57.62 & [45] \\
\hline $\mathrm{CHA} / \mathrm{MFC}$ & $\mathrm{SO}_{4}^{-2}\left(\mathrm{Na}_{2} \mathrm{SO}_{4}\right)$ & $\begin{array}{l}9.89 \\
\text { (Sips) }\end{array}$ & This study \\
\hline $\mathrm{CHA} / \mathrm{MFC}$ & $\mathrm{SO}_{4}^{-2}(\mathrm{SLS})$ & $\begin{array}{l}26.40 \\
\text { (Sips) }\end{array}$ & This study \\
\hline
\end{tabular}


Table 6. $R^{2}$ value for isotherm modes using different error functions in case of SLS.

\begin{tabular}{clllll}
$\begin{array}{l}\text { Error } \\
\text { function }\end{array}$ & Langmuir & Sips & Freudlich & Toth & R-P \\
\hline SSE & 0.7379 & 0.8468 & 0.7149 & 0.7368 & 0.7477 \\
ARE & 0.0269 & -1.3821 & -0.6669 & 0.0643 & 0.0720 \\
X $^{2}$ & 0.7290 & 0.7981 & 0.6899 & 0.7316 & 0.7435 \\
X $_{\text {red }}^{2}$ & 0.7290 & 0.7981 & 0.6899 & 0.7316 & 0.7435 \\
HYBRID & 0.82110 & 0.84348 & 0.81488 & 0.82116 & 0.82115 \\
MPSD & 0.3817 & 0.5707 & 0.5206 & 0.3324 & 0.3324
\end{tabular}


Table 7. $\mathrm{R}^{2}$ value for isotherm modes using different error functions in case of $\mathrm{Na}_{2} \mathrm{SO}_{4}$.

\begin{tabular}{cllllll}
$\begin{array}{l}\text { Error } \\
\text { function }\end{array}$ & Langmuir & Sips & Freudlich & Toth & R-P \\
\hline SSE & 0.7515 & 0.7984 & 0.7856 & 0.7998 & 0.7992 \\
ARE & 0.7487 & 0.7258 & 0.6936 & 0.7181 & 0.7326 \\
X $^{2}$ & 0.7497 & 0.7966 & 0.7845 & 0.7980 & 0.7974 \\
X $_{\text {red }}^{2}$ & 0.7497 & 0.7966 & 0.7845 & 0.7980 & 0.7974 \\
HYBRID & 0.7462 & 0.7949 & 0.7797 & 0.7966 & 0.7961 \\
MPSD & 0.7291 & 0.7866 & 0.7666 & 0.7889 & 0.7883
\end{tabular}


Values of error functions with different isotherm models for sulfates of SLS after the parameters were optimized to the values represented in Table 3.

Error Langmuir Sips Freundlich $\quad$ Toth R-P

function

\begin{tabular}{cccccc}
\hline SSE & 268.6 & 157.1 & 292.2 & 269.8 & 258.6 \\
ARE & 35.85 & 66.65 & 65.98 & 35.01 & 34.87 \\
$X^{2}$ & 18.29 & 11.32 & 20.36 & 18.23 & 17.08 \\
X $_{\text {red }}^{2}$ & 3.049 & 2.263 & 3.394 & 3.646 & 3.415 \\
HYBRID & 334.0 & 173.0 & 328.6 & 400.8 & 400.7 \\
MPSD & 19.89 & 20.58 & 17.47 & 23.76 & 23.76
\end{tabular}

Magnitude of variation of data values for sulfates of SLS, when different error functions were used. The values are differences between the maximum and the minimum. For example, if considering Langmuir isotherm model and concentration $310.20 \mathrm{mg} / \mathrm{L}$, use of error function $A R E$ led to modeled adsorption capacity 16.69 , and $\mathrm{X}^{2}$ error produced value 32.04 , the difference being 15.35 .

\begin{tabular}{cccccc} 
Ce & Langmuir & Sips & Freundlich & Toth & R-P \\
\hline 19.14 & 2.35 & 1.07 & 3.04 & 2.31 & 2.03 \\
38.58 & 4.38 & 2.68 & 4.39 & 4.28 & 4.00 \\
77.13 & 7.53 & 8.85 & 6.93 & 7.39 & 7.51 \\
104.16 & 9.30 & 15.53 & 9.36 & 9.18 & 9.61 \\
138.96 & 11.20 & 22.51 & 12.57 & 11.00 & 11.76 \\
117.66 & 10.10 & 19.51 & 10.61 & 9.94 & 10.52 \\
276.00 & 15.04 & 26.84 & 24.51 & 14.40 & 13.96 \\
310.20 & 15.35 & 27.39 & 27.35 & 14.57 & 13.21 \\
\hline average & $\mathbf{9 . 4 0}$ & $\mathbf{1 5 . 5 5}$ & $\mathbf{1 2 . 3 4}$ & $\mathbf{9 . 1 3}$ & $\mathbf{9 . 0 8}$
\end{tabular}


Magnitude of variation of data values in SLS modeling, obtained with different isotherm models, separately for each error measure. For example, when the concentration was 38.58 $\mathrm{mg} / \mathrm{L}$ and SSE error was used, the SIPS isotherm produced the smallest modeled value 0.05 , whereas Freundlich isotherm gave the highest one 6.73 , the difference between them being 6.68 .

\begin{tabular}{ccccccc}
$\mathrm{Ce}$ & SSE & ARE & chi-square & red. chi-square & HYBRID & MPSD \\
\hline 19.14 & 4.03 & 0.04 & 2.99 & 2.99 & 1.84 & 0.52 \\
38.58 & 6.68 & 1.75 & 3.64 & 3.64 & 3.69 & 0.46 \\
77.13 & 6.68 & 2.42 & 1.08 & 1.08 & 3.15 & 0.63 \\
104.16 & 3.49 & 3.79 & 2.30 & 2.30 & 7.88 & 1.57 \\
138.96 & 7.49 & 5.62 & 3.85 & 3.85 & 10.35 & 2.83 \\
117.66 & 6.39 & 4.50 & 3.16 & 3.16 & 10.33 & 2.06 \\
276.00 & 1.96 & 13.08 & 2.22 & 2.22 & 3.09 & 6.80 \\
310.20 & 4.47 & 14.96 & 4.80 & 4.80 & 6.74 & 8.40 \\
\hline average & $\mathbf{5 . 1 5}$ & $\mathbf{5 . 7 7}$ & $\mathbf{3 . 0 0}$ & $\mathbf{3 . 0 0}$ & $\mathbf{5 . 8 8}$ & $\mathbf{2 . 9 1}$
\end{tabular}

Absolute errors of each model for each experimental concentration for SLS. The averages on the last line. The fitting criteria used was SSE.

\begin{tabular}{cccccc}
$\mathrm{C}_{\mathrm{e}}$ & Langmuir & Sips & Freundlich & Toth & R-P \\
\hline 19.14 & 2.31 & 1.07 & 2.97 & 2.31 & 2.03 \\
38.58 & 4.39 & 2.01 & 4.67 & 4.36 & 4.09 \\
77.13 & 7.45 & 0.87 & 6.93 & 7.36 & 7.55 \\
104.16 & 1.70 & 0.90 & 2.59 & 1.83 & 1.22 \\
138.96 & 1.59 & 4.79 & 2.70 & 1.76 & 0.72 \\
117.66 & 9.71 & 4.33 & 10.72 & 9.87 & 9.06 \\
276.00 & 8.16 & 6.47 & 8.43 & 8.11 & 8.19
\end{tabular}


Absolute differences between the models corresponding each experimental values for sulfates of SLS, and the averages on the last line. The fitting criteria was SSE.

\begin{tabular}{ccccccccccc} 
& & Lan.- & Lan.- & & Sips- & Sips- & Sips-R- & Freu.- & \multicolumn{2}{c}{ Freu-R- } \\
Ce & Lan.-Sips & Freu. & Toth & Lan.-R-P & Freu & Toth & P & Toth & P & $P$ \\
\hline 19.14 & 3.38 & 0.65 & 0.01 & 0.29 & 4.03 & 3.38 & 3.09 & 0.66 & 0.94 & 0.28 \\
38.58 & 6.40 & 0.27 & 0.03 & 0.30 & 6.68 & 6.37 & 6.10 & 0.30 & 0.57 & 0.27 \\
77.13 & 6.58 & 0.52 & 0.10 & 0.10 & 6.06 & 6.48 & 6.68 & 0.43 & 0.62 & 0.19 \\
104.16 & 2.60 & 0.89 & 0.14 & 0.48 & 3.49 & 2.74 & 2.12 & 0.75 & 1.37 & 0.62 \\
138.96 & 6.39 & 1.11 & 0.17 & 0.87 & 7.49 & 6.56 & 5.51 & 0.94 & 1.98 & 1.04 \\
117.66 & 5.39 & 1.01 & 0.15 & 0.65 & 6.39 & 5.54 & 4.73 & 0.86 & 1.66 & 0.80 \\
276.00 & 1.69 & 0.27 & 0.05 & 0.03 & 1.96 & 1.64 & 1.72 & 0.32 & 0.24 & 0.08 \\
310.20 & 3.47 & 1.01 & 0.04 & 0.74 & 4.47 & 3.50 & 2.73 & 0.97 & 1.74 & 0.77 \\
\hline average & 4.49 & 0.72 & 0.08 & 0.43 & 5.07 & 4.53 & 4.09 & 0.65 & 1.14 & 0.51
\end{tabular}

Values of error functions with different isotherm models for sulfates of $\mathrm{Na}_{2} \mathrm{SO}_{4}$ after the parameters were optimized to the values represented in Table 4.

\begin{tabular}{cccccc} 
& Langmuir & SIPS & Freundlich & Toth & R-P \\
\hline SSE & 4.510 & 3.657 & 3.891 & 3.632 & 3.644 \\
ARE & 11.08 & 9.105 & 9.348 & 8.705 & 8.732 \\
$X^{2}$ & 0.7954 & 0.7107 & 0.7667 & 0.6897 & 0.6935 \\
$X_{\text {red }}^{2}$ & 0.1326 & 0.1421 & 0.1278 & 0.1379 & 0.1387 \\
HYBRID & 13.79 & 13.22 & 11.64 & 12.86 & 12.94 \\
MPSD & 6.529 & 7.103 & 6.091 & 6.921 & 6.958
\end{tabular}


Magnitude of variation of data values for sulfates of $\mathrm{Na}_{2} \mathrm{SO}_{4}$ obtained with different error measures for each isotherm model (differences between the maximum and the minimum of the values obtained with different error functions).

\begin{tabular}{cccccc} 
Ce & Langmuir & Sips & Freundlich & Toth & R-P \\
\hline 8.60 & 0.22 & 0.33 & 0.68 & 0.40 & 0.41 \\
14.90 & 0.24 & 0.48 & 0.67 & 0.61 & 0.54 \\
69.30 & 0.27 & 0.70 & 0.56 & 0.74 & 0.63 \\
123.30 & 0.29 & 0.61 & 0.48 & 0.60 & 0.53 \\
153.00 & 0.30 & 0.53 & 0.43 & 0.51 & 0.47 \\
216.00 & 0.31 & 0.39 & 0.36 & 0.36 & 0.37 \\
267.00 & 0.31 & 0.25 & 0.30 & 0.23 & 0.28 \\
456.00 & 0.32 & 0.18 & 0.13 & 0.19 & 0.14 \\
\hline average & $\mathbf{0 . 2 8}$ & $\mathbf{0 . 4 3}$ & $\mathbf{0 . 4 5}$ & $\mathbf{0 . 4 5}$ & $\mathbf{0 . 4 2}$
\end{tabular}

Magnitude of variation of data values for $\mathrm{Na}_{2} \mathrm{SO}_{4}$ obtained with different isotherm models for each error measure (differences between the maximum and the minimum obtained with different isotherm models).

\begin{tabular}{ccccccc} 
Ce & SSE & ARE & chi-square & square & HYBRID & MPSD \\
\hline 8.60 & 0.56 & 0.13 & 0.44 & 0.44 & 0.35 & 0.22 \\
14.90 & 0.11 & 0.50 & 0.12 & 0.12 & 0.17 & 0.25 \\
69.30 & 0.65 & 1.11 & 0.70 & 0.70 & 0.70 & 0.69 \\
123.30 & 0.45 & 0.83 & 0.47 & 0.47 & 0.44 & 0.40 \\
153.00 & 0.29 & 0.63 & 0.30 & 0.30 & 0.26 & 0.19 \\
216.00 & 0.05 & 0.30 & 0.06 & 0.06 & 0.09 & 0.16 \\
267.00 & 0.21 & 0.06 & 0.22 & 0.22 & 0.29 & 0.41 \\
456.00 & 0.85 & 0.82 & 0.89 & 0.89 & 0.99 & 1.17 \\
\hline average & $\mathbf{0 . 3 9}$ & $\mathbf{0 . 5 5}$ & $\mathbf{0 . 4 0}$ & $\mathbf{0 . 4 0}$ & $\mathbf{0 . 4 1}$ & $\mathbf{0 . 4 4}$
\end{tabular}

Absolute errors of each model for each experimental concentration $\left(\mathrm{Na}_{2} \mathrm{SO}_{4}\right)$, and the average differences on the list line. The fitting criteria used was SSE 


\begin{tabular}{cccccc} 
Ce & Langmuir & Sips & Freudlich & Toth & R-P \\
\hline 8.60 & 0.12 & 0.44 & 0.68 & 0.40 & 0.41 \\
14.90 & 0.67 & 0.74 & 0.63 & 0.67 & 0.68 \\
69.30 & 1.08 & 0.59 & 0.43 & 0.63 & 0.62 \\
120.00 & 1.13 & 0.83 & 0.68 & 0.82 & 0.82 \\
153.00 & 1.18 & 1.34 & 1.47 & 1.37 & 1.36 \\
210.00 & 0.13 & 0.10 & 0.15 & 0.13 & 0.12 \\
267.00 & 0.05 & 0.23 & 0.26 & 0.21 & 0.23 \\
456.00 & 0.47 & 0.09 & 0.38 & 0.13 & 0.17 \\
\hline Average & $\mathbf{0 . 6 0}$ & $\mathbf{0 . 5 5}$ & $\mathbf{0 . 5 8}$ & $\mathbf{0 . 5 4}$ & $\mathbf{0 . 5 5}$
\end{tabular}

Absolute differences between the models corresponding each experimental values and the average differences on the last line for $\mathrm{Na}_{2} \mathrm{SO}_{4}$.

\begin{tabular}{cccccccccccc}
\multicolumn{1}{c}{ Lang. - } & Lang. - & Lang. - & Lang. - & Sips- & \multicolumn{2}{c}{ Sips- } & \multicolumn{2}{c}{ Sips - } & \multicolumn{2}{c}{ Freu.- } & \multicolumn{2}{c}{ Freu- } & Toth- \\
Ce & Sips & Freu. & Toth & R-P & Freu & Toth & R-P & Toth & R-P & R-P \\
\hline 8.60 & 0.31 & 0.56 & 0.27 & 0.29 & 0.24 & 0.04 & 0.02 & 0.28 & 0.27 & 0.02 \\
14.90 & 0.07 & 0.03 & 0.00 & 0.02 & 0.11 & 0.07 & 0.06 & 0.04 & 0.05 & 0.01 \\
69.30 & 0.48 & 0.65 & 0.44 & 0.46 & 0.16 & 0.04 & 0.02 & 0.20 & 0.19 & 0.01 \\
120.00 & 0.29 & 0.45 & 0.30 & 0.30 & 0.16 & 0.01 & 0.01 & 0.14 & 0.14 & 0.00 \\
153.00 & 0.17 & 0.29 & 0.19 & 0.18 & 0.12 & 0.03 & 0.02 & 0.10 & 0.10 & 0.01 \\
210.00 & 0.02 & 0.03 & 0.01 & 0.01 & 0.05 & 0.03 & 0.02 & 0.02 & 0.04 & 0.02 \\
267.00 & 0.18 & 0.21 & 0.16 & 0.18 & 0.03 & 0.02 & 0.00 & 0.05 & 0.03 & 0.02 \\
456.00 & 0.56 & 0.85 & 0.60 & 0.63 & 0.29 & 0.04 & 0.08 & 0.25 & 0.22 & 0.04 \\
\hline Average & $\mathbf{0 . 2 6}$ & $\mathbf{0 . 3 8}$ & $\mathbf{0 . 2 5}$ & $\mathbf{0 . 2 6}$ & $\mathbf{0 . 1 5}$ & $\mathbf{0 . 0 4}$ & $\mathbf{0 . 0 3}$ & $\mathbf{0 . 1 4}$ & $\mathbf{0 . 1 3}$ & $\mathbf{0 . 0 2}$
\end{tabular}

